\title{
A generalized stress correction scheme for the MEB rheology: impact on the fracture angles and deformations
}

\author{
Mathieu Plante ${ }^{1}$ and L. Bruno Tremblay ${ }^{1}$ \\ ${ }^{1}$ Department of Atmospheric and Oceanic Sciences, McGill University, Montréal, Québec, Canada \\ Correspondence: Mathieu Plante (mathieu.plante@mail.mcgill.ca)
}

\begin{abstract}
A generalized damage parameterization is developed for the Maxwell Elasto-Brittle (MEB) rheology that reduces the growth of residual errors associated with the correction of super-critical stresses. In the generalized parameterization, a decohesive stress tensor is used to bring the super-critical stresses back on the yield curve based on any correction path. The sensitivity of the simulated material behaviour to the magnitude of the decohesive stress tensor is investigated in uniaxial compression simulations. Results show that while the decohesive stress tensor influences the short-term fracture deformation and orientation, the long-term post-fracture behaviour remains unchanged. Divergence first occurs when the elastic response is dominant followed by post-fracture shear and convergence when the viscous response dominates - contrary to laboratory experiment of granular flow and satellite imagery in the Arctic. The post-fracture deformations are shown to be dissociated from the fracture process itself, an important difference with classical Viscous Plastic (VP) models. Using the generalized damage parameterization together with a stress correction path normal to the yield curve brings the simulated fracture angles closer to observations (from $40-50^{\circ}$ to $35-45^{\circ}$, compared to $20-30^{\circ}$ in observations) and reduces the growth of errors sufficiently for the production of longer-term simulations.
\end{abstract}

\section{Introduction}

Sea ice is a thin layer of solid material that insulates the polar oceans from the cold atmosphere. When sea ice fractures and a lead (or Linear Kinematic Features, LKFs) opens, large heat and moisture fluxes take place between the ocean and the atmosphere, significantly affecting the polar meteorology on short time-scales and the climate system on long time-scales (Maykut, 1982; Ledley, 1988; Lüpkes et al., 2008; Li et al., 2020). The refreezing of leads significantly contributes to the sea ice mass balance (Wilchinsky et al., 2015; Itkin et al., 2018), and the associated brine rejection drives the thermohaline ocean circulation in the Arctic and vertical eddies in the ocean mixed layer (Kozo, 1983; Matsumura and Hasumi, 2008). As such, the production of accurate seasonal-to-decadal projections using coupled models requires an accurate representation of sea ice leads. Furthermore, the presence and deformations along LKFs can influence the pressure on ships and increase the risk of besetting (Mussells et al., 2017; Lemieux et al., 2020). The increased navigation through the Arctic passages (Pizzolato 
et al., 2016; Aksenov et al., 2017) thus calls for the development of high-resolution sea ice forecast products that capture the finer-scale lead structures (Jung et al., 2016).

As sea ice models are moving to higher spatial resolutions, they become increasingly capable of resolving LKFs (Hutter et al., 2019; Bouchat and Tremblay, 2020). The simulation of the ice fractures yet represents a challenge. To this day, most sea ice models simulate the motion of sea ice using plastic rheologies or modifications thereof (Hibler, 1979; Hunke, 2001). While several improvements were made on the numerics and efficiency of the methods used to solve the highly non-linear momentum equation (Hunke, 2001; Lemieux et al., 2008, 2014; Kimmritz et al., 2016; Koldunov et al., 2019), the physics governing the ice fracture remains mostly the same. A number of rheologies have however been developed over the years in an attempt to simulate the observed sea-ice deformations (Tremblay and Mysak, 1997; Wilchinsky and Feltham, 2004; Schreyer et al., 2006; Sulsky and Peterson, 2011; Rampal et al., 2016; Dansereau et al., 2016; Damsgaard et al., 2018). Among these new approaches, a damage parameterization derived for rock mechanics and seismology models (Amitrano et al., 1999; Amitrano and Helmstetter, 2006) was adapted for the large scale modelling of sea ice (Girard et al., 2011; Bouillon and Rampal, 2015). This parameterization uses a damage parameter to represent the changes in material properties associated with fractures. While still based on the continuum assumption, it allows for fractures to propagate on short time-scales in the sea-ice cover. It is used in the Elasto-Brittle (EB Bouillon and Rampal, 2015; Rampal et al., 2016) and Maxwell Elasto-Brittle (MEB Dansereau et al., 2016) rheologies, implemented in the large scale sea-ice Finite Element model neXtSIM (Rampal et al., 2019) and, recently, in the Finite Difference McGill sea ice model (Plante et al., 2020).

The damage parameterization is relatively new, and it remains unclear to what extent differences in material behaviour are associated with the damage or to other rheological parameters. One known difference is the fracture development associated with local damage, stress concentration and damage propagation, rather than prescribed by an associative normal flow rule as in the standard VP models. The fracture angle simulated by the MEB and standard VP models are nonetheless in the same range $\left(\theta=35-55^{\circ}\right.$, Dansereau et al., 2019; Hutter et al., 2020), which is larger than those derived from high-resolution satellite observations $\left(\theta=20-45^{\circ}\right.$ Hutter et al., 2019) and in-situ observations $\left(\theta=20-30^{\circ}\right.$ Marko and Thomson, 1977; Schulson, 2004). In the standard VP model, modifications of the mechanical strength parameters (compressive and shear) and the use of non-associated flow rules lead to smaller fracture angles that are more in line with observations (Ringeisen et al., 2019, 2020). In the MEB rheology, the fracture angles can be reduced by increasing the angle of internal friction or the Poisson ratio (Dansereau et al., 2019). These sensitivities suggest that modifications to the damage parameterization could be used to bring the simulated fracture angles closer to observations, but has not yet been tested.

The MEB rheology also presents some numerical challenges associated with the growth of residual errors associated with the damage parameterization at the grid scale (Plante et al., 2020). These errors can be attributed to the stress correction scheme, a numerical tool used to define the growth of damage and to bring the super-critical stresses back to the yield curve. Other progressive damage models instead represent the damage parameter as a discrete function of the number of failure cycles (Main, 2000; Amitrano and Helmstetter, 2006; Carrier et al., 2015). In continuum damage mechanics, a damage potential derived from thermodynamic laws (Murakami, 2012) is used to simulate the material fatigue. In the Elastic-Decohesive (ED) 
https://doi.org/10.5194/tc-2020-354

Preprint. Discussion started: 2 February 2021

(c) Author(s) 2021. CC BY 4.0 License.

(c) (i)

rheology, material damage is not parameterized but a decohesive strain rate explicitly represents the material discontinuity associated with the ice fracture and reduces the material strength of sea-ice (Schreyer et al., 2006; Sulsky and Peterson, 2011).

In this paper, we present a generalization of the damage parameterization that reduces the growth of the residual errors associated with the stress correction and brings the simulated fracture angle of sea ice in simple uniaxial loading experiments closer to observations. Inspired by the work of Schreyer et al. (2006) and (Sulsky and Peterson, 2011), we introduce a decohesive stress associated with the fracture of sea ice and test its influence on the simulated sea-ice fracture and deformations in uniaxial loading experiments.

The paper is organised as follows. In section 2, we present the MEB rheology and governing equations. The generalized stress correction scheme is described in section 3. The uniaxial loading experimental set-up is presented in section 4 along with the definition of diagnostics used to quantify the growth of damage and the growth of residual errors. Results are presented in section 5, with a focus on the material behaviour in uniaxial compression experiments and its response to the changes in the damage parameterization. In section 6 , we discuss the influence of the stress correction and seeded heterogeneity. Conclusions are summarized in section 7 .

\section{Model}

\subsection{Momentum and continuity equations}

The simulations are run using the MEB model implemented on a Eulerian Arakawa C-grid in the McGill Sea Ice Model Version 5 (McGill SIM5, Tremblay and Mysak, 1997; Lemieux et al., 2008; Plante et al., 2020). The vertically integrated

2D momentum equation for sea ice, forced with surface friction only (i.e. ignoring the sea surface tilt, the coriolis and the ice grounding terms), can be written as:

$\rho_{i} h \frac{\partial \boldsymbol{u}}{\partial t}=\nabla \cdot \boldsymbol{\sigma}+\boldsymbol{\tau}$

where $\rho_{i}$ is the ice density, $h$ is the mean ice thickness, $\boldsymbol{u}(=u \hat{\boldsymbol{i}}+v \hat{\boldsymbol{j}})$ is the ice velocity vector, $\boldsymbol{\sigma}$ is the vertically integrated internal stress tensor and $\tau$ is the net external surface stress from winds and ocean currents. This simplified formulation is appropriate for short term uniaxial loading experiments but can result in small errors in ice velocity when using a realistic model domain and forcing (Turnbull et al., 2017). Following (Plante et al., 2020), we define the uniaxial loading by a surface wind stress $\tau_{a}$ and prescribe an ocean at rest below the ice:

$\boldsymbol{\tau} \approx \boldsymbol{\tau}_{a}-\rho_{w} C_{d w}|\boldsymbol{u}| \boldsymbol{u}$

where $\rho_{w}$ is the water density, $C_{d w}$ is the water drag coefficient and $\boldsymbol{u}$ is the sea ice velocity (see values in Table 1).

The prognostic equations for the mean ice thickness $h$ (volume per grid cell area) and concentration $A$ are written as:

$\frac{\partial h}{\partial t}+\nabla \cdot(h \boldsymbol{u})=0$ 
$\frac{\partial A}{\partial t}+\nabla \cdot(A \boldsymbol{u})=0$

where the thermodynamic source an sink terms are ignored.

\section{0}

\subsection{Maxwell Elasto Brittle Rheology}

In the MEB rheology, the ice behaves as a visco-elastic material with a fast elastic response and a viscous response over a longer-time scale. The governing equation for this visco-elastic material can be written as (Dansereau et al., 2016, 2017; Plante et al., 2020):

$$
\frac{\partial \boldsymbol{\sigma}}{\partial t}+\frac{1}{\lambda} \boldsymbol{\sigma}=E \mathbf{C}: \dot{\boldsymbol{\epsilon}}
$$

where $E$ is the elastic stiffness defined as the vertically integrated Young Modulus of sea ice, $\lambda$ is the viscous relaxation timescale, $\mathbf{C}$ is the elastic tensor (fourth order), ":" denotes the inner double tensor product and $\dot{\epsilon}$ is the strain rate tensor. The elastic tensor $\mathbf{C}$ and strain rate tensor $\dot{\boldsymbol{\epsilon}}$ can be written is matrix form as:

$$
\mathbf{C}=\frac{1}{1-\nu^{2}}\left(\begin{array}{ccc}
1 & \nu & 0 \\
\nu & 1 & 0 \\
0 & 0 & 1-\nu
\end{array}\right)
$$

$100\left(\begin{array}{c}\dot{\epsilon}_{11} \\ \dot{\epsilon}_{22} \\ \dot{\epsilon}_{12}\end{array}\right)=\left(\begin{array}{c}\frac{\partial u}{\partial x} \\ \frac{\partial v}{\partial y} \\ \frac{1}{2}\left(\frac{\partial u}{\partial y}+\frac{\partial v}{\partial x}\right)\end{array}\right)$

where $\nu(=0.33)$ is the Poisson ratio, which defines the relative amount of deformation on the plane parallel to the loading.

The relative importance of the elastic and viscous components (first and second terms on the left hand side in Eq. 5) are determined by the magnitude of the elastic modulus $E$ and viscous relaxation time-scale $\lambda . E$ and $\lambda$ are functions of the ice thickness, concentration and damage resulting in dominant elastic component for small deformations (undamaged ice) and dominant viscous component for large deformations (heavily fractured ice). The elastic modulus $E$ and viscous relaxation time-scale $\lambda$ are written as:

$E=Y h e^{-a(1-A)}(1-d)$,

$\lambda=\lambda_{0}(1-d)^{\alpha-1}$,

where $\mathrm{Y}(=1 \mathrm{GPa})$ is the Young Modulus of undeformed sea ice, $d$ is the damage parameter $(0<d<1), a(=20)$ is the standard parameter ruling the dependency of the material strength properties on sea-ice concentration (Hibler, 1979; Rampal et al., 2016), $\lambda_{0}\left(=10^{5} \mathrm{~s}, \approx 1\right.$ day) is the viscous relaxation time scale for undamaged sea ice and $\alpha$ is a parameter ruling the post-fracture transition to the viscous regime. 
https://doi.org/10.5194/tc-2020-354

Preprint. Discussion started: 2 February 2021

(c) Author(s) 2021. CC BY 4.0 License.

(c) (i)

\subsection{Yield criterion}

Damage (or fracture) occurs when the internal stress state exceeds the Mohr-Coulomb failure criterion,

$F(\sigma)=\sigma_{I I}+\mu \sigma_{I}-c<0$

where $\sigma_{I}$ is the isotropic normal stress invariant (compression defined as negative), $\sigma_{I I}$ is the maximum shear stress invariant, $\mu(=\sin \phi)$ is the coefficient of internal friction of ice, $\phi\left(=45^{\circ}\right)$ is the angle of internal friction, and $c$ is the vertically integrated cohesion, defined as:

$c=c_{0} h e^{-a(1-A)}$,

where $c_{0}\left(=10 \mathrm{kN} \mathrm{m}^{-2}\right)$ is the cohesion of sea ice derived from observations (Sodhi, 1997; Tremblay and Hakakian, 2006; Plante et al., 2020) or laboratory experiments (Timco and Weeks, 2010). No compressive or tensile strength cut-off are used in this analysis. The reader is referred to Table 1 for a list of default model parameters.

\subsection{Damage parameterization}

The prognostic equation for the damage parameter $d$ in the standard MEB rheology is parameterized using a relaxation term with time scale $T_{d}(=1 \mathrm{~s})$ as:

$\frac{\partial d}{\partial t}=\frac{(1-\Psi)(1-d)}{T_{d}}$

where

$\Psi=\frac{\boldsymbol{\sigma}_{c}}{\boldsymbol{\sigma}^{\prime}}=\min \left(1, \frac{c}{\sigma_{I I}^{\prime}+\mu \sigma_{I}^{\prime}}\right)$

is a damage factor $(0<\Psi<1), \boldsymbol{\sigma}_{c}$ is the critical stress lying on the yield curve and $\boldsymbol{\sigma}^{\prime}$ is the uncorrected stress state lying outside of the yield curve. Thermodynamic healing and advection are neglected as we are focusing on the ice fracture.

When the ice fractures, the damage factor $\Psi$ is used to scale the super-critical stresses back towards the yield curve. The prognostic equation for the temporal evolution of the super-critical stress tensor $\boldsymbol{\sigma}^{\prime}$ is written as a relaxation equation of the same form as in Eq. 12:

$\frac{\partial \boldsymbol{\sigma}^{\prime}}{\partial t}=-\frac{(1-\Psi) \boldsymbol{\sigma}^{\prime}}{T_{d}}$.

\section{Generalized stress correction}

We propose a generalized damage parameterization where the super-critical stresses are corrected back to the yield curve along a line oriented at any angle $\gamma$ from the y-axis in the stress invariant space (see Fig. 1). To this end, we chose to define the damage factor in terms of the shear stress invariant only, as:

$\Psi=\frac{\sigma_{I I c}}{\sigma_{I I}^{\prime}}$, 
https://doi.org/10.5194/tc-2020-354

Preprint. Discussion started: 2 February 2021

(c) Author(s) 2021. CC BY 4.0 License.

(c) (i)

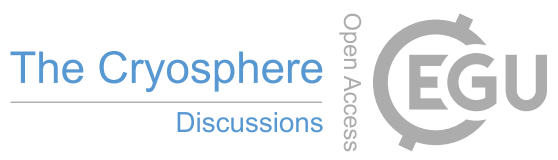

140 where the critical shear stress invariant $\sigma_{I I c}$ is defined by the intersection point between the correction path and the yield curve (see Fig 1). After some algebra, we obtain:

$\sigma_{I I c}=\frac{c+\mu \tan (\gamma) \sigma_{I I}^{\prime}-\mu \sigma_{I}^{\prime}}{1+\mu \tan (\gamma)}$

The damage factor can then be written in terms of the super-critical stress state invariants $\left(\sigma_{I}^{\prime}, \sigma_{I I}^{\prime}\right)$, the correction path angle $\gamma$ and the coefficient of internal friction $\mu$, as:

$\Psi=\frac{c+\mu \tan (\gamma) \sigma_{I I}^{\prime}-\mu \sigma_{I}^{\prime}}{(1+\mu \tan (\gamma)) \sigma_{I I}^{\prime}}$

In this manner, the correction of super-critical stresses can follow any line in the stress invariant space provided that the damage increases when ice fractures $\left(\Psi<1\right.$, or $\left.\gamma<90^{\circ}\right)$. The generalized formulation now allows for the use of a yield curve without cohesion $\left(c=0 \mathrm{kN} \mathrm{m}^{-1}\right)$, something that is not possible in the standard parameterization otherwise $\Psi$ is identically equal to 0 (see Eq. 13).

Note that using a stress correction path other than the standard path to the origin means that the corrected normal stress differs from the scaled super-critical stress $\Psi \sigma_{I}^{\prime}$. We define this difference as the decohesive stress tensor needed to for the corrected stress to follow the stress correction path $\gamma$ (see Fig. 1). The stress correction equation (Eq. 14) then becomes:

$\frac{\partial \boldsymbol{\sigma}^{\prime}}{\partial t}=-\frac{(1-\Psi) \boldsymbol{\sigma}^{\prime}+\boldsymbol{\sigma}_{D}}{T_{d}}$.

The invariants of the decohesive stress tensor $\left(\sigma_{I D}, \sigma_{I I D}\right)$ are therefore written as:

$\sigma_{I D}=\sigma_{I c}-\Psi \sigma_{I}^{\prime}=\frac{c-\Psi\left(\sigma_{I I}^{\prime}-\mu \sigma_{I}^{\prime}\right)}{\mu}$,

$\sigma_{I I D}=0$, (by definition).

When $\tan \gamma=\sigma_{I}^{\prime} / \sigma_{I I}^{\prime}$ and $\sigma_{I D}=\sigma_{I I D}=0$, we obtain the standard damage parameterization of Dansereau et al. (2016) as a special case where the stress correction path depends on the super-critical stress state. Note that the decohesive stress tensor used in this parameterization has a similar role as the decohesive strain rates used in the Elastic-Decohesive model Schreyer et al. (2006), in that they both determine the change in stress state associated with the development of a fracture. In the present scheme, $\boldsymbol{\sigma}_{D}$ is derived from the stress correction path, while the decohesive strain rate in Schreyer et al. (2006) is derived from the opening of a lead based on granular theory.

\subsection{Projected error}

The error $\delta \Psi$ on the damage factor $\Psi\left(\sigma_{I}^{\prime}, \sigma_{I I}^{\prime}\right)$ can be written as:

$\delta \Psi=\sqrt{\left(\frac{\partial \Psi}{\partial \sigma_{I}^{\prime}}\right)^{2} \delta \sigma_{I}^{\prime 2}+\left(\frac{\partial \Psi}{\partial \sigma_{I I}^{\prime}}\right)^{2} \delta \sigma_{I I}^{\prime 2}}$ 
where $\left(\delta \sigma_{I}^{\prime}, \delta \sigma_{I I}^{\prime}\right)$ are the errors on the calculated stress invariants. Expanding the derivative terms (using Eq. 18) and re-writing $\delta \sigma_{I}^{\prime}$ and $\delta \sigma_{I I}^{\prime}$ in terms of the relative error $\epsilon$ (i.e., $\delta \sigma_{I}^{\prime}=\epsilon \sigma_{I}^{\prime}, \delta \sigma_{I I}^{\prime}=\epsilon \sigma_{I I}^{\prime}$ ), we obtain:

$$
\begin{aligned}
\delta \Psi & =\sqrt{\frac{\mu^{2}}{(1+\mu \tan (\gamma))^{2} \sigma_{I I}^{\prime 2}} \epsilon^{2} \sigma_{I}^{\prime 2}+\frac{\left(c-\mu \sigma_{I}^{\prime}\right)^{2}}{(1+\mu \tan (\gamma))^{2} \sigma_{I I}^{\prime 4}} \epsilon^{2} \sigma_{I I}^{\prime 2}}, \\
& =\Psi \epsilon \sqrt{\frac{\mu^{2} \sigma_{I}^{\prime 2}+\left(c-\mu \sigma_{I}^{\prime}\right)^{2}}{\left(c+\mu \tan (\gamma) \sigma_{I I}^{\prime}-\mu \sigma_{I}^{\prime}\right)^{2}}},
\end{aligned}
$$

where $\mathrm{R}$ is the error amplification ratio.

Assuming that the uncorrected stress is close to the yield criterion (i.e. $\sigma_{I I}^{\prime}+\mu \sigma_{I}^{\prime}-c \sim 0$ ), this relation indicates that the error amplification ratio $R$ goes to infinity if:

$\tan (\gamma)=-1 / \mu$

which corresponds to a path that runs parallel to the yield curve. This result is consistent with the instabilities in the standard stress correction scheme during ridging reported in Plante et al. (2020), given that a line passing through the origin is nearly parallel to the Mohr Coulomb yield curve for large compressive stresses. In contrast, the path that maximizes the denominator (smallest error growth) has $\gamma=90^{\circ}$. This path, however, correspond to $\Psi=1$ and does not create damage. The possible stress correction path angles $\gamma$ thus lie in the range $\arctan (-1 / \mu)<\theta<90^{\circ}$.

Note that the error amplification ratio $R$ is small for $\sigma_{I}<0$, but becomes infinitely large at the yield curve tip when $\sigma_{I I}^{\prime}$ approaches 0 (see Eq. 22). This behaviour is opposite to that of the standard stress correction scheme, which has small $R$ values in tension and large values in compression (Plante et al., 2020). To minimize the errors for all stress states, we blend the two schemes (i.e. Eq. 17 in compression and Eq. 13 in tension, see Fig. 1b). We set the transition between the two schemes at the points where they are both equal (i.e., at $\sigma_{I}^{\prime} / \sigma_{I I}^{\prime}=\tan \gamma$, see green line in Fig 1b). The damage factor is then defined as:

$\Psi= \begin{cases}\frac{c+\mu \gamma \sigma_{I I}^{\prime}-\mu \sigma_{I}^{\prime}}{(1+\mu \gamma) \sigma_{I I}^{\prime}}, & \text { if } \sigma_{I}^{\prime}<\sigma_{I I}^{\prime} \tan \gamma \\ \frac{c}{\sigma_{I I}^{\prime}+\mu \sigma_{I}^{\prime}}, & \text { otherwise. }\end{cases}$

\section{Methods}

\subsection{Numerical approaches}

The MEB model is implemented in the McGill Sea Ice Model Version 5 (McGill SIM5) using an Eulerian, 2nd order finite difference numerical scheme (Tremblay and Mysak, 1997; Lemieux et al., 2014; Plante et al., 2020). The equations are discretized in space using an Arakawa C-grid and in time using a semi-implicit backward Euler scheme (Plante et al., 2020). A solution to the non-linear momentum and constitutive equations (Eqs. 1 and 5) is found using a Picard solver. The Picard solver uses an outer loop in which the equations are linearized and solved at each iteration using a preconditioned Flexible General Minimum RESidual method (FGMRES, Lemieux et al., 2008). The non-linear terms are then updated and the linear problem solved again until the residual error $\epsilon_{\text {res }}$, defined as the L2-norm of the solution vector, is lower than $10^{-8} \mathrm{~N} / \mathrm{m}^{2}$. The 
https://doi.org/10.5194/tc-2020-354

Preprint. Discussion started: 2 February 2021

(c) Author(s) 2021. CC BY 4.0 License.

(c) (i)

prognostic equations for the tracers (Eq. 3, 4 and 12) are updated within the outer loop iteration using an IMplicit-EXplicit (IMEX) approach (Lemieux et al., 2014). The reader is referred to Plante et al. (2020) for more details.

\subsection{Experiment setup}

Following Ringeisen et al. (2019); Dansereau et al. (2019); Herman (2016), we present results from idealized uniaxial loading experiments and test the sensitivity of the residual error growth on the correction path angle $\gamma$ in the generalized stress correction scheme. The model domain is $250 \times 100 \mathrm{~km}$ (with $1 \mathrm{~km}$ resolution), with sea ice of $1 \mathrm{~m}$ thickness and $100 \%$ concentration in the middle $60 \mathrm{~km}$ of the domain and two narrow bands of open water (20 km width) on each sides (Fig. 2). A solid Dirichlet boundary condition $(u=v=0)$ is used at the bottom, and open Neumann boundary conditions $(\partial u / \partial n=0)$ are used on the top and sides. In all experiments, the forcing is specified by a surface stress $\tau_{a}$ (see Eq. 2). This differs from Ringeisen et al. (2019) and Dansereau et al. (2016) where the upper boundary is represented by a moving wall acting as external forcing. The forcing $\tau_{a}$ is ramped up from 0 to $0.60 \mathrm{~N} / \mathrm{m}^{2}$ (corresponding to $\sim 20 \mathrm{~m} / \mathrm{s}$ winds or $\sim 0.33 \mathrm{~m} / \mathrm{s}$ surface currents) in a $2 \mathrm{~h}$ period, and then remains constant.

\subsection{Diagnostics definitions}

\subsubsection{Field asymmetry}

We monitor the growth of the residual error in the simulations using a normalised domain-integrated asymmetry factor $\left(\epsilon_{\text {asym }}\right)$ in the maximum shear stress invariant field $\left(\sigma_{I I}\right)$, defined as:

$210 \epsilon_{\text {asym }}=\frac{\sum_{i=a}^{b} \sum_{j=1}^{n y}\left|\sigma_{I I}(i, j)-\sigma_{I I}(n x-i, j)\right|}{\sum_{i=a}^{b} \sum_{j=1}^{n y}\left|\sigma_{I I}(i, j)\right|}$,

where (i,j) are the $x$-y grid indices respectively, (nx,ny) are the number of grid cells in the $x$ and $y$-directions and $(a, b)$ are the indices of the first and last ice-covered grid cells on the $\mathrm{x}$-axis.

\subsubsection{Damage activity}

We define the damage activity $D$ as the total damage integrated over the original ice domain in a 1 minute interval:

$215 D=\sum_{i=a}^{b} \sum_{j=1}^{n y} \frac{d(i, j)^{t+30 s}-d(i, j)^{t-30 s}}{60 s}$.

This parameter is analog to the damage rate in (Dansereau et al., 2016, 2017). Note that this definition of damage activity (or damage rate) emphasizes activity in undamaged ice and is not sensitive to activity in already heavily damaged ice.

\subsubsection{Fracture angle}

When loaded in uniaxial compression, a granular material fails in diamond-shaped shear fractures (e.g. see Marko and Thom-

son, 1977; Ringeisen et al., 2019). We define the fracture angle $\theta$ as the angle between the $y$-axis and the fracture lines (see 
Fig. 2). The orientation of these fracture lines have been measured in laboratory using in uniaxial loading experiments. Several theories were developed to relate the fracture angle in terms of material parameters. The most common is the Mohr-Coulomb theory (Coulomb, 1773; Mohr, 1900), where the fracture angle is related to the angle of internal friction as:

$\theta=\frac{\pi}{4}-\frac{\phi}{2}$

This theory tends to underestimate the fracture angle of granular materials in laboratory experiments (Bardet, 1991). In the Roscoe (1970) theory, the fracture angle is defined instead in terms of the angle of dilatancy $(\delta)$ of the granular material:

$\theta=\frac{\pi}{4}-\frac{\delta}{2}$

If $\delta=\phi$, the two theories give the same fracture angle $\theta$. In general, the fracture angle falls between values predicted by the Mohr-Coulomb and Roscoe theories with zero dilatancy $(\delta=0)$ (Arthur et al., 1977; Bardet, 1991).

In our experiment, the fracture angle is calculated graphically for each individual simulation. We define the uncertainty as $\pm \tan (W / L) \sim \pm 2^{\circ}$, where $W$ is the fracture width (typically a few grid cells wide in our results, or $\sim 2-5 \mathrm{~km}$ ) and $L$ is the fracture length $(\sim 45 \mathrm{~km})$. This error increases to $\pm 6^{\circ}$ for the few cases where the fracture is not well defined.

\section{Results}

\subsection{Control simulation: standard damage parameterization}

235 In the control simulation, a pair of conjugate fracture lines first appear when the surface forcing $\tau_{a}=0.29 \mathrm{~N} / \mathrm{m}$, along with secondary fracture lines that are the results of interactions between the ice floe and the solid boundary that extends across the full width of the domain at the base (Fig. 3). All fracture lines are oriented at $39^{\circ}$ from the y-axis, smaller than reported by Dansereau et al. (2019) using a Finite Element implementation of the same model $\left(\theta=\sim 43^{\circ}\right)$ and in the high range seen in observations $\left(\theta=\sim 20-40^{\circ}\right.$ Marko and Thomson, 1977; Hibler III and Schulson, 2000; Schulson, 2004; Hutter et al., 2020).

This orientation also falls in between that predicted by the Mohr-Coulomb $\left(\theta=22.5^{\circ}\right)$ and Roscoe theories $\left(\theta=45^{\circ}\right.$ when $\delta=0$ ), in accord with the common observation that both the angle of internal friction and the dilatancy $(\delta)$ are important in defining the fracture (Arthur et al., 1977; Vardoulakis, 1980; Balendran and Nemat-Nasser, 1993).

When the ice fractures, the initial response is mostly elastic with divergence along the fracture line. The resulting stress concentration influences the propagation of the fracture in space over short time-scales (seconds) governed by the elastic waves speed. The sea-ice deformation continues to occur post-fracture in the damaged ice and, over time, the response transitions from elastic to viscous-dominated as the Maxwell viscosity dissipates the elastic stresses and creates permanent viscous deformations. This transition is clearly seen in the development of a linear dependence between stress and strain-rate invariants scaled by $(1-d)^{3}$, where the slope corresponds to the viscosity (see for instance $4 \mathrm{c}, \mathrm{f}, \mathrm{i}$ ). The simulation reaches steady state with deformations that are fully viscous and localized in the heaviest damage areas (Fig. 4g-i). This causes a predominance of shear and convergence deformation along the fracture line throughout the simulation. 
The asymmetries in the solution are very small at the beginning of the simulation $(\mathrm{t} \leq 57 \mathrm{~min})$, and do not grow until fractures occur (Fig. 5a-b). As the fractures develop, small errors grow rapidly with $\epsilon_{\text {asym }}$ increasing in large steps crossing multiple orders of magnitude. Note that the model is always iterated to convergence with a strict residual error tolerance $\left(\epsilon_{\text {res }}=10^{-6} \mathrm{Nm}^{-2}\right.$ ). The growth in $\epsilon_{\text {asym }}$ are associated with large values of damage error amplification ratio $R$ (reaching $\sim 20$, Fig. 5 b). Since $\epsilon_{\text {asym }}$ is a domain-integrated quantity, it increases in time following large local error growths $R$. This illustrates the long-range and long-term influence of residual errors, which act on the development of the future fractures. Note that $\epsilon_{\text {asym }}$ saturates when the $\sigma_{I I}$ field is no longer symmetric, and becomes insensitive to additional error growth. We assess the precision of the solution using the maximum error amplification ratio $R_{\max }$, which indicate the level of amplification of residual errors in the simulations, at times by more than one order of magnitude locally $\left(R_{\max }>10\right)$.

\subsection{Generalized stress correction}

The generalized damage parameterization reduces the growth of residual errors, with decreasing error amplification ratio $R_{\max }$ for increasing path angle $\gamma$ (Fig. 6a). This results in an overall reduction of the asymmetry factor $\epsilon_{\text {asym }}$ (Fig. 6b), allowing for the production of longer-term simulations that include post-fracture deformations. This improvement is only significant when using $\gamma>0$. For $\gamma<0$, the maximum error amplification ratio $R_{\max }$ remains important with periods when the residual error increases by up to two orders of magnitude locally.

Results show that the fracture angle is sensitive to the decohesive stress tensor, with decreasing fracture angle $\theta$ for increasing stress correction path angle $\gamma$ (Fig. 7). This finding is in line with results from Dansereau et al. (2019), where the fracture angle was related to the far-field stress associated with the collective damage. In the MEB model, the far-field stresses directly depends on corrected stress state, including $\sigma_{D}$ in the generalized damage parameterization. Increasing the correction path angle $\gamma$ reduces the fracture angles in better agreement to observations.

Along the fracture lines, the correction path angle $\gamma$ influences the time-integration required to reach the same damage and deformation rates (Fig. 8). This due to the fact that increasing the angle $\gamma$ reduces the amount of damage for the same super-critical stress state because the stress correction path approaches the horizontal and $\Psi$ is closer to 1 . The simulated ice deformations are otherwise mostly insensitive to the correction path angle; i.e. all simulations have divergence during the initial elastic response when the ice fractures followed by a transition to viscous deformations where shear and convergence deformations are predominant (Fig. 8a). In contrast with results from the VP model and from typical granular material behaviour, divergent post-fracture deformation is only present when tensile stresses develop, e.g. at the intersection between conjugate lines of fracture.

\subsection{Sensitivity to $\phi$ and $\nu$}

Repeating the experiment using different angles of internal friction $(\phi)$ shows that the fracture angle decreases with increasing $\phi$. The simulated fracture angles fall within the envelope from the Mohr-Coulomb and Roscoe theories, except for small angles of internal friction $\left(\phi<20^{\circ}\right)$, a value that is rarely observed for granular materials (Fig. 9). Note that the sensitivity of the fracture angle to the coefficient of internal friction also disappears for small angles of internal friction $\left(\phi<20^{\circ}\right)$ when using 
a large correction path angle ( $\gamma=60^{\circ}$ in Fig. 7). When both the stress correction path and the yield criterion approaches the horizontal, fracture yields large stress corrections but small damage increases (i.e., $\Psi=1$ ), such that the angle of fracture is governed by the stress correction and is weakly sensitive other model parameters. Based on these results, we suggest the use of a correction path that is normal to the yield criterion ( $\gamma=\arctan \mu$, see black points in Fig. 9).

Decreasing the angle of internal friction reduces the shear strength of sea ice for a given normal stress, such that the fracture develops earlier in the simulation (i.e. under smaller surface forcing, Fig. 10). It also reduces the divergence associated with the elastic response when ice fractures and increase the convergence in the post-fracture viscous regime. This result is typical for granular material, with smaller fracture angles associated with larger angles of dilatancy and divergence during the fracture development.

The fracture angle is not sensitive to the Poisson ratio when the generalized stress correction scheme is used with a fixed stress correction path angle $\gamma$ (Fig 11). This is in contrast with simulations using the standard stress correction scheme, where the fracture angle decreases with increasing $\nu$ (see blue points in Fig. 11, and also in Dansereau et al., 2019). Note that the Poisson ratio also affects the amount of shear and normal stress concentration associated with a local discontinuity in material properties (Karimi and Barrat, 2018). The fact that the fracture angle is not affected by the changes in Poisson ratio thus indicates that the stress concentration and propagation of the fracture in space is mainly controlled by the stress correction rather than by the relaxation of material properties with damage. We speculate that the sensitivity of the fracture angle to the Poisson ratio in the standard stress correction scheme stems from the dependency of the stress correction path angle to the super-critical stress state (i.e. $\gamma=\tan ^{-1}\left(\sigma_{I}^{\prime} / \sigma_{I I}^{\prime}\right)$ ).

\section{Discussion}

The results presented above show that the generalized stress correction scheme reduces the growth of the residual error associated with the damage parameterization. Despite the improvement, some asymmetries are still present in the simulations $\left(\epsilon_{\text {asym }}<10^{-2}\right)$. This is due to the memory in the damage parameter (i.e. an integrated quantity) where residual errors accumulate and influence the temporal evolution of the solution. In regions of heavily damaged ice, the accumulated errors in the damage parameter result in large errors in the stress state due to the cubic dependence of the Maxwell viscosity $\eta$ on $d$ (Eq. 9). Future work includes replacing this formulation with a function that decreases the sensitivity of the Maxwell viscosity $\eta$ for small changes in $d$ around $d=1$.

Overall, the use of a decohesive stress tensor yields smaller simulated fracture angles, without significantly impacting the material deformations. Using a large correction path angle $\gamma\left(>45^{\circ}\right)$, however, significantly slows the damage production and reduces the simulated sensitivity of the fracture angle to the mechanical strength parameters. Based on these results, we suggest using a correction path that is normal to the yield criterion $(\gamma=\arctan \mu)$. This value brings the simulated fracture angles closer to observations (see black points in Fig. 9) and reduces the amplification of residual errors, while correcting the super-critical stresses towards the closest point on the yield curve. 
The simulation results show that in the MEB model, the damage develops at short time scales during which the elastic component of the rheology is important, while most of the deformations occur post-fracture over a longer time scale in the heavily damaged ice. This is in stark contrast with plastic models, in which a flow rule simultaneously dictates both the fracture development and the relative amount of shear and normal deformations occurring in the fractures. The decoupling between the development of damage and the post-fracture deformations in the MEB model explains that the type of deformations in the fracture remains similar (uniaxial convergence, i.e. ridging, contrary to observation, Stern et al., 1995) despite the use of different stress correction path $\gamma$. This behaviour stems from the dominance of the viscous regime post-fracture: lead opening cannot occur when the stress state is compressive and remains limited to locations where tensile stresses are present, such as at the intersection of lines of fracture. This is contrary to granular theories, in which the distribution of contact normals determines the amount of ridging or lead opening (i.e. dilatancy) that is occurring when forced in uniaxial compression (Balendran and Nemat-Nasser, 1993). This indicates that the decohesive stress tensor cannot be used to influence the deformations associated to the fracture of ice in the MEB rheology unless other parameterizations, such as including a decohesive strain tensor during the fractures (e.g., see Schreyer et al., 2006; Sulsky and Peterson, 2011), are added to the rheology.

The viscous dissipation timescale $(\lambda)$ in our model is set based on observations $\left(\sim 10^{5}\right.$, Tabata, 1955 ; Hata and Tremblay, 2015), and is one order of magnitude smaller than in other MEB implementations (Dansereau et al., 2016; Rampal et al., 2019). The results from the model are robust to the exact value of $\lambda$ for a range $10^{5}-10^{7}$; the increase $\lambda$ being compensated by larger damage values along the fracture lines. For even larger $\lambda$ values, divergence deformations persist longer in the simulation and the transition from elastic- to viscous-dominated regime occurs later in the simulation (see Fig. 12), decreasing the overall convergence along the fractures lines. If the transition to the viscous regime is removed (e.g. by setting $\alpha=1$ ), divergence dominates throughout the simulations and reach large values as the leads open. The elastic wave are however nolonger dissipated in the fractures, leading to large and noisy deformation fields (divergence/convergence). These findings call for a different viscosity-dependence on damage leading to both dissipation of elastic waves and a more realistic post-fracture deformation field.

Note that the results presented above neglect heterogeneity in the ice cover, a factor that is responsible for much of the brittle material behaviour in progressive damage models (Amitrano and Helmstetter, 2006). Heterogeneity was neglected in the analysis above to isolate the growth of the residual errors. While including heterogeneities does not change the overall physics and sensitivity to the damage parameterization, it creates irregular sliding planes instead of the linear diamond shape fractures (Fig. 13a), naturally creating contact points where ridging occurs with lead opening elsewhere along the fracture lines. This results in a form of granular dilatancy typical of granular materials.

\section{7 conclusion}

We propose a generalized stress correction scheme for the damage parameterization to reduce the growth of residual errors in the MEB sea ice model. To this end, we scale the damage factor $\Psi$ based on the super-critical maximum shear stress invariant $\left(\sigma_{I I}^{\prime}\right)$ only, together with a decohesive stress tensor defining the path from the super-critical stress state to the yield curve. 
https://doi.org/10.5194/tc-2020-354

Preprint. Discussion started: 2 February 2021

(c) Author(s) 2021. CC BY 4.0 License.

(c) (i)

The sensitivity of the fracture angles and sea-ice deformations to these changes are investigated in the context of the uniaxial compression experiment similar to those presented in Ringeisen et al. (2019).

Our results show that in the MEB rheology, most of the deformations occur post-fracture in heavily damaged ice, where the viscous term is dominant. This causes a predominance of convergence (ridging) in the fractures, contrary to laboratory experiments of granular materials and satellite observations of sea ice. The use of a decohesive stress tensor influences the fracture angle of sea ice, but does not influence the type of deformation rates (convergence and shear), nor the simulated dilatancy. Future work will involve the modification of the non-linear relationship between the Maxwell viscosity and the damage. We also show that the sensitivity of the fracture angle to the Poisson ratio, seen when using the standard damage parameterization, disappears when using the generalizes stress correction scheme with a fixed stress correction path. This suggests that in the MEB model, the stress concentration and fracture propagation is governed by the stress correction rather than by the relaxation of the mechanical properties associated with the damage.

Based on our results, using the generalized damage parameterization with a stress correction path normal to the yield curve reduces the growth of residual errors and allows for the production of longer term simulations with post-fracture deformations. Using this stress correction path also reduces the fracture angles by $\sim 5^{\circ}$, bringing them in the range of observations. Despite these improvements, some error growth remains inherent to the formulation of the damage parameterization. Whether this might be improved by removing the dependency of the damage parameters on the damage factor (and on the super-critical stress state) will be explored in future work.

Code availability. Our sea-ice model code and outputs are available upon request.

Author contributions. M. Plante coded the model, ran all the simulations, analyzed results and led the writing of the manuscript. B. Tremblay participated in regular discussions during the course of the work and edited the manuscript.

Competing interests. The authors declare that they have no conflict of interest.

Acknowledgements. Our sea-ice model code and outputs are available upon request. Mathieu Plante would like to thank the Fonds de recherche du Québec - Nature et technologies (FRQNT) for financial support received during the course of this work. Bruno Tremblay is grateful for support from the Natural Science and Engineering and Research Council (NSERC) Discovery Program and the Office of Naval Research (N000141110977). This work is a contribution to the research program of Québec-Océan and of the ArcTrain International Training Program. 
https://doi.org/10.5194/tc-2020-354

Preprint. Discussion started: 2 February 2021

(c) Author(s) 2021. CC BY 4.0 License.

(c) (i)

\section{References}

Aksenov, Y., Popova, E. E., Yool, A., Nurser, A. J. G., Williams, T. D., Bertino, L., and Bergh, J.: On the future navigability of Arctic sea routes : High-resolution projections of the Arctic Ocean and sea ice, Marine Policy, 75, 300-317, https://doi.org/10.1016/j.marpol.2015.12.027, http://dx.doi.org/10.1016/j.marpol.2015.12.027, 2017.

Amitrano, D. and Helmstetter, A.: Brittle creep, damage and time to failure in rocks, Journal of Geophysical Research : Solid Earth, 111, B11 201, https://doi.org/10.1029/2005JB004252, https://hal.archives-ouvertes.fr/hal-00172671, 2006.

Amitrano, D., Grasso, J.-R., and Hantz, D.: From diffuse to localised damage through elastic interaction, Geophysical Research Letters, 26, 2109-2112, 1999.

Arthur, J. R. F., Dunstan, T., Al-Ani, Q. A. J. L., and Assadi, A.: Plastic deformation and failure in granular media, Géotechnique, 27, 53-74, https://doi.org/10.1680/geot.1977.27.1.53, https://doi.org/10.1680/geot.1977.27.1.53, 1977.

Balendran, B. and Nemat-Nasser, S.: DOUBLE SLIDING MODEL FOR CYCLIC MATERIALS , EFFECTS DEFORMATION INCLUDING OF GRANULAR, J. Mech. Phys. Solids, 41, 1993.

Bardet, J.: Orientation of shear bands in frictional soils, Journal of Engineering Mechanics - ASCE, 117, 1466-1484, https://doi.org/10.1061/(ASCE)0733-9399(1991)117:7(1466), 1991.

Bouchat, A. and Tremblay, B.: Scaling and statistical properties of sea-ice deformation fields from models participating in the FAMOS Sea-Ice Rheology Experiment, To be submitted to JGR, 2020.

Bouillon, S. and Rampal, P.: Presentation of the dynamical core of neXtSIM, a new sea ice model, Ocean Modelling, 91, 23-37, https://doi.org/10.1016/j.ocemod.2015.04.005, http://dx.doi.org/10.1016/j.ocemod.2015.04.005, 2015.

Carrier, A., Got, J.-L., Peltier, A., Ferrazzini, V., Staudacher, T., Kowalski, P., and Boissier, P.: A damage model for volcanic edifices: Implications for edifice strength, magma pressure, and eruptive processes, Journal of Geophysical Research: Solid Earth, 120, 567-583, https://doi.org/10.1002/2014JB011485, https://agupubs.onlinelibrary.wiley.com/doi/abs/10.1002/2014JB011485, 2015.

Coulomb, C.: Test on the applications of the rules of maxima and minima to some problems of statics related to architecture, Mem Math Phys, 7, 343-382, 1773.

Damsgaard, A., Adcroft, A., and Sergienko, O.: Application of Discrete Element Methods to Approximate Sea Ice Dynamics, Journal of Advances in Modeling Earth Systems, 10, 2228-2244, https://doi.org/10.1029/2018MS001299, https://agupubs.onlinelibrary.wiley.com/ doi/abs/10.1029/2018MS001299, 2018.

Dansereau, V., Weiss, J., Saramito, P., and Lattes, P.: A Maxwell elasto-brittle rheology for sea ice modelling, The Cryosphere, 10, 13391359, https://doi.org/10.5194/tc-10-1339-2016, 2016.

Dansereau, V., Weiss, J., Saramito, P., Lattes, P., and Coche, E.: Ice bridges and ridges in the Maxwell-EB sea ice rheology, The Cryosphere, 11, 2033-2058, 2017.

Dansereau, V., Démery, V., Berthier, E., Weiss, J., and Ponson, L.: Collective Damage Growth Controls Fault Orientation in Quasibrittle Compressive Failure, Phys. Rev. Lett., 122, 085 501, https://doi.org/10.1103/PhysRevLett.122.085501, https://link.aps.org/doi/10.1103/ PhysRevLett.122.085501, 2019.

Girard, L., Bouillon, S., Weiss, J., Amitrano, D., Fichefet, T., and Legat, V.: A new modeling framework for sea-ice mechanics based on elasto-brittle rheology, Annals of Glaciology, 52, 123-132, https://doi.org/10.3189/172756411795931499, 2011.

410 Hata, Y. and Tremblay, L. B.: Anisotropic internal thermal stress in sea ice from the Canadian Arctic Archipelago, Journal of Geophysical Research: Oceans, 120, 5457-5472, https://doi.org/10.1002/2015JC010819.Received, 2015. 
https://doi.org/10.5194/tc-2020-354

Preprint. Discussion started: 2 February 2021

(c) Author(s) 2021. CC BY 4.0 License.

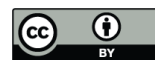

Herman, A.: Discrete-Element bonded-particle Sea Ice model DESIgn, version 1.3a - model description and implementation, Geoscientific Model Development, 9, 1219-1241, https://doi.org/10.5194/gmd-9-1219-2016, https://gmd.copernicus.org/articles/9/1219/2016/, 2016.

Hibler, W. D.: A dynamic thermodynamic sea ice model, Journal of Physical Oceanography, 9, 815-846, 1979.

Hibler III, W. D. and Schulson, E. M.: On modeling the anisotropic failure and flow of flawed sea ice, Journal of Geophysical Research: Oceans, 105, 17 105-17 120, https://doi.org/10.1029/2000JC900045, https://agupubs.onlinelibrary.wiley.com/doi/abs/10.1029/ 2000JC900045, 2000.

Hunke, E. C.: Viscous-Plastic Sea Ice Dynamics with the EVP Model: Linearization Issues, Journal of Computational Physics, 170, 18 - 38, https://doi.org/https://doi.org/10.1006/jcph.2001.6710, http://www.sciencedirect.com/science/article/pii/S0021999101967105, 2001.

Hutter, N., Zampieri, L., and Losch, M.: Leads and ridges in Arctic sea ice from RGPS data and a new tracking algorithm, The Cryosphere, 13, 627-645, https://doi.org/10.5194/tc-13-627-2019, https://tc.copernicus.org/articles/13/627/2019/, 2019.

Hutter, N., Bouchat, A., Dupont, F., Dukhovskoy, D., Koldunov, N., Lee, Y., Lique, C., Maslowski, W., Myers, P., Olason, E., Rasmussen, T., Tremblay, B., and Wang, Q.: Leads and pressure ridges simulated by high-resolution sea-ice models within the FAMOS Sea Ice rheology experiments (SIREx), To be submitted to JGR, 2020.

Itkin, P., Spreen, G., Hvidegaard, S. M., Skourup, H., Wilkinson, J., Gerland, S., and Granskog, M. A.: Contribution of Deformation to Sea Ice Mass Balance: A Case Study From an N-ICE2015 Storm, Geophysical Research Letters, 45, 789-796, https://doi.org/10.1002/2017GL076056, https://agupubs.onlinelibrary.wiley.com/doi/abs/10.1002/2017GL076056, 2018.

Jung, T., Gordon, N. D., Bauer, P., Bromwich, D. H., Chevallier, M., Day, J. J., Dawson, J., Doblas-Reyes, F., Fairall, C., Goessling, H. F., Holland, M., Inoue, J., Iversen, T., Klebe, S., Lemke, P., Losch, M., Makshtas, A., Mills, B., Nurmi, P., Perovich, D., Reid, P., Renfrew, I. A., Smith, G., Svensson, G., Tolstykh, M., and Yang, Q.: Advancing Polar Prediction Capabilities on Daily to Seasonal Time Scales, Bulletin of the American Meteorological Society, 97, 1631-1647, https://doi.org/10.1175/BAMS-D-14-00246.1, https://doi.org/10.1175/ BAMS-D-14-00246.1, 2016.

Karimi, K. and Barrat, J.-L.: Correlation and shear bands in a plastically deformed granular medium, Scientific Reports, 8, 4021, https://doi.org/10.1038/s41598-018-22310-z, https://doi.org/10.1038/s41598-018-22310-z, 2018.

Kimmritz, M., Danilov, S., and Losch, M.: The adaptive EVP method for solving the sea ice momentum equation, Ocean Modelling, 101, 59 67, https://doi.org/https://doi.org/10.1016/j.ocemod.2016.03.004, http://www.sciencedirect.com/science/article/pii/S1463500316300038, 2016.

Koldunov, N. V., Danilov, S., Sidorenko, D., Hutter, N., Losch, M., Goessling, H., Rakowsky, N., Scholz, P., Sein, D., Wang, Q., and Jung, T.: Fast EVP Solutions in a High-Resolution Sea Ice Model, Journal of Advances in Modeling Earth Systems, 11, 1269-1284, https://doi.org/10.1029/2018MS001485, https://agupubs.onlinelibrary.wiley.com/doi/abs/10.1029/2018MS001485, 2019.

Kozo, T. L.: Initial model results for Arctic mixed layer circulation under a refreezing lead, Journal of Geophysical Research: Oceans, 88, 2926-2934, https://doi.org/10.1029/JC088iC05p02926, https://agupubs.onlinelibrary.wiley.com/doi/abs/10.1029/JC088iC05p02926, 1983.

Ledley, T. S.: A coupled energy balance climate-sea ice model: Impact of sea ice and leads on climate, Journal of Geophysical Research: Atmospheres, 93, 15 919-15 932, https://doi.org/10.1029/JD093iD12p15919, https://agupubs.onlinelibrary.wiley.com/doi/abs/10. 1029/JD093iD12p15919, 1988.

Lemieux, J.-F., Tremblay, B., Thomas, S., Sedláček, J., and Mysak, L. A.: Using the preconditioned Generalized Minimum RESidual ( GMRES ) method to solve the sea-ice momentum equation, Journal of Geophysical Research, 113, C10004, https://doi.org/10.1029/2007JC004680, 2008. 
https://doi.org/10.5194/tc-2020-354

Preprint. Discussion started: 2 February 2021

(c) Author(s) 2021. CC BY 4.0 License.

(c) (i)

Lemieux, J.-f., Knoll, D. A., Losch, M., and Girard, C.: A second-order accurate in time IMplicit - EXplicit ( IMEX ) integration scheme for sea ice dynamics, Journal of Computational Physics, 263, 375-392, https://doi.org/10.1016/j.jcp.2014.01.010, http://dx.doi.org/10.1016/ j.jcp.2014.01.010, 2014.

Lemieux, J.-F., Tremblay, B., and Plante, M.: Toward a method for downscaling sea ice pressure, The Cryosphere Discussions, 2020, 1-26, https://doi.org/10.5194/tc-2020-134, https://tc.copernicus.org/preprints/tc-2020-134/, 2020.

Li, X., Krueger, S. K., Strong, C., Mace, G. G., and Benson, S.: Midwinter Arctic leads form and dissipate low clouds, Nature Communications, 11, 206, https://doi.org/10.1038/s41467-019-14074-5, https://doi.org/10.1038/s41467-019-14074-5, 2020.

Lüpkes, C., Vihma, T., Birnbaum, G., and Wacker, U.: Influence of leads in sea ice on the temperature of the atmospheric boundary layer during polar night, Geophysical Research Letters, 35, https://doi.org/10.1029/2007GL032461, https://agupubs.onlinelibrary.wiley.com/ doi/abs/10.1029/2007GL032461, 2008.

Main, I. G.: A damage mechanics model for power-law creep and earthquake aftershock and foreshock sequences, Geophysical Journal International, 142, 151-161, https://doi.org/10.1046/j.1365-246x.2000.00136.x, https://doi.org/10.1046/j.1365-246x.2000.00136.x, 2000.

Marko, J. R. and Thomson, R. E.: Rectilinear leads and internal motions in the ice pack of the western Arctic Ocean, Journal of Geophysical Research (1896-1977), 82, 979-987, https://doi.org/10.1029/JC082i006p00979, https://agupubs.onlinelibrary.wiley.com/doi/abs/10.1029/ JC082i006p00979, 1977.

Matsumura, Y. and Hasumi, H.: Brine-Driven Eddies under Sea Ice Leads and Their Impact on the Arctic Ocean Mixed Layer, Journal of Physical Oceanography, 38, 146-163, https://doi.org/10.1175/2007JPO3620.1, https://doi.org/10.1175/2007JPO3620.1, 2008.

Maykut, G. A.: Large-scale heat exchange and ice production in the central Arctic, Journal of Geophysical Research: Oceans, 87, 7971-7984, https://doi.org/10.1029/JC087iC10p07971, https://agupubs.onlinelibrary.wiley.com/doi/abs/10.1029/JC087iC10p07971, 1982.

Mohr, O.: Welche Umstände bedingen die Elastizitätsgrenze und den Bruch eines Materials, Zeitschrift des Vereins Deutscher Ingenieure, 46, 1572-1577, 1900.

Murakami, S.: Continuum damage mechanics : a continuum mechanics approach to the analysis of damage and fracture, https://doi.org/10.1007/978-94-007-2666-6, http://site.ebrary.com/id/10537681, 2012.

Mussells, O., Dawson, J., and Howell, S.: Navigating pressured ice: Risks and hazards for winter resource-based shipping in the Canadian Arctic, Ocean and Coastal Management, 137, 57 - 67, https://doi.org/https://doi.org/10.1016/j.ocecoaman.2016.12.010, http://www. sciencedirect.com/science/article/pii/S0964569116303969, 2017.

Pizzolato, L., Howell, S. E. L., Dawson, J., Laliberté, F., and Copland, L.: The influence of declining sea ice on shipping activity in the Canadian Arctic, Geophysical Research Letters, 43, 12,146-12,154, https://doi.org/10.1002/2016GL071489, https://agupubs.onlinelibrary. wiley.com/doi/abs/10.1002/2016GL071489, 2016.

Plante, M., Tremblay, B., Losch, M., and Lemieux, J.-F.: Landfast sea ice material properties derived from ice bridge simulations using the Maxwell elasto-brittle rheology, The Cryosphere, 14, 2137-2157, https://doi.org/10.5194/tc-14-2137-2020, https://tc.copernicus.org/ articles/14/2137/2020/, 2020.

Rampal, P., Bouillon, S., Ólason, E., and Morlighem, M.: neXtSIM: a new Lagrangian sea ice model, The Cryosphere, 10, 1055-1073, https://doi.org/10.5194/tc-10-1055-2016, https://www.the-cryosphere.net/10/1055/2016/, 2016.

Rampal, P., Dansereau, V., Olason, E., Bouillon, S., Williams, T., and Samaké, A.: On the multi-fractal scaling properties of sea ice deformation, The Cryosphere Discussions, 2019, 1-45, https://doi.org/10.5194/tc-2018-290, https://www.the-cryosphere-discuss.net/ tc-2018-290/, 2019. 
https://doi.org/10.5194/tc-2020-354

Preprint. Discussion started: 2 February 2021

(c) Author(s) 2021. CC BY 4.0 License.

(c) (i)

Ringeisen, D., Losch, M., Tremblay, L. B., and Hutter, N.: Simulating intersection angles between conjugate faults in sea ice with different viscous-plastic rheologies, The Cryosphere, 13, 1167-1186, https://doi.org/10.5194/tc-13-1167-2019, https://www.the-cryosphere.net/ 13/1167/2019/, 2019.

Ringeisen, D., Tremblay, L. B., and Losch, M.: Non-normal flow rules affect fracture angles in sea ice viscous-plastic rheologies, The Cryosphere Discussions, 2020, 1-24, https://doi.org/10.5194/tc-2020-153, https://tc.copernicus.org/preprints/tc-2020-153/, 2020.

Roscoe, K. H.: The Influence of Strains in Soil Mechanics, Géotechnique, 20, 129-170, https://doi.org/10.1680/geot.1970.20.2.129, https: //doi.org/10.1680/geot.1970.20.2.129, 1970.

Schreyer, H. L., Sulsky, D. L., Munday, L. B., Coon, M. D., and Kwok, R.: Elastic-decohesive constitutive model for sea ice, Journal of Geophysical Research: Oceans, 111, C11S26, https://doi.org/10.1029/2005JC003334, 2006.

Schulson, E. M.: Compressive shear faults within arctic sea ice: Fracture on scales large and small, Journal of Geophysical Research: Oceans, 109, https://doi.org/10.1029/2003JC002108, https://agupubs.onlinelibrary.wiley.com/doi/abs/10.1029/2003JC002108, 2004.

Sodhi, D. S.: Ice arching and the drift of pack ice through restricted channels, Cold Regions Research and Engineering Laboratory (CRREL) Rep. 77-18, p. 11 pp., 1997.

Stern, H. L., Rothrock, D. A., and Kwok, R.: Open water production in Arctic sea ice: Satellite measurements and model parameterizations, Journal of Geophysical Research: Oceans, 100, 20 601-20 612, https://doi.org/10.1029/95JC02306, https://agupubs.onlinelibrary.wiley. com/doi/abs/10.1029/95JC02306, 1995.

Sulsky, D. and Peterson, K.: Toward a new elastic - decohesive model of Arctic sea ice, Physica D Nonlinear Phenomena, 240, 1674-1683, https://doi.org/10.1016/j.physd.2011.07.005, 2011.

505 Tabata, T.: A measurement of Visco-Elastic Constants of Sea Ice, Journal of the Oceanographical Society of Japan, 11, 185-189, 1955.

Timco, G. W. and Weeks, W. F.: A review of the engineering properties of sea ice, Cold Regions Science and Technology, 60, 107-129, https://doi.org/10.1016/j.coldregions.2009.10.003, http://dx.doi.org/10.1016/j.coldregions.2009.10.003, 2010.

Tremblay, L.-B. and Hakakian, M.: Estimating the Sea Ice Compressive Strength from Satellite-Derived Sea Ice Drift and NCEP Reanalysis Data, Journal of Physical Oceanography, 36, 2165-2172, 2006.

510 Tremblay, L.-B. and Mysak, L. A.: Modeling Sea Ice as a Granular Material , Including the Dilatancy Effect, Journal of Physical Oceanography, 27, 2342-2360, 1997.

Turnbull, I. D., Torbati, R. Z., and Taylor, R. S.: Relative influences of the metocean forcings on the drifting ice pack and estimation of internal ice stress gradients in the Labrador Sea, Journal of Geophysical Research: Oceans, 122, 5970-5997, https://doi.org/10.1002/2017JC012805, https://agupubs.onlinelibrary.wiley.com/doi/abs/10.1002/2017JC012805, 2017.

Vardoulakis, I.: Shear band inclination and shear modulus of sand in biaxial tests, International Journal for Numerical and Analytical Methods in Geomechanics, 4, 103-119, https://doi.org/10.1002/nag.1610040202, https://onlinelibrary.wiley.com/doi/abs/10.1002/nag. $1610040202,1980$.

Wilchinsky, A. V. and Feltham, D. L.: A continuum anisotropic model of sea-ice dynamics, Proceedings of the Royal Society of London. Series A: Mathematical, Physical and Engineering Sciences, 460, 2105-2140, https://doi.org/10.1098/rspa.2004.1282, https: //royalsocietypublishing.org/doi/abs/10.1098/rspa.2004.1282, 2004.

Wilchinsky, A. V., Heorton, H. D. B. S., Feltham, D. L., and Holland, P. R.: Study of the Impact of Ice Formation in Leads upon the Sea Ice Pack Mass Balance Using a New Frazil and Grease Ice Parameterization, Journal of Physical Oceanography, 45, 2025-2047, https://doi.org/10.1175/JPO-D-14-0184.1, https://doi.org/10.1175/JPO-D-14-0184.1, 2015. 
https://doi.org/10.5194/tc-2020-354

Preprint. Discussion started: 2 February 2021

(c) Author(s) 2021. CC BY 4.0 License.

Table 1. Default Model Parameters

\begin{tabular}{lll}
\hline Parameter & Definition & Value \\
\hline$\Delta x$ & Spatial resolution & $1 \mathrm{~km}$ \\
$\Delta t$ & Time step & $0.2 \mathrm{~s}$ \\
$T_{d}$ & Damage time scale & $1 \mathrm{~s}$ \\
$\mathrm{Y}$ & Young Modulus & $10^{9} \mathrm{n} \mathrm{m}^{-2}$ \\
$\nu$ & Poisson ratio & 0.33 \\
$\lambda_{0}$ & Viscous relaxation time & $10^{5} \mathrm{~s}$ \\
$\alpha$ & Viscous transition parameter & 3 \\
$\phi$ & Angle of internal friction & $45^{\circ}$ \\
$c_{0}$ & Cohesion & $10 \mathrm{~N} \mathrm{~m}^{-2}$ \\
$\sigma_{c_{0}}$ & Isotropic compressive strength & $50 \mathrm{~N} \mathrm{~m}^{-2}$ \\
$\rho_{a}$ & Air density & $1.3 \mathrm{~kg} \mathrm{~m}^{-3}$ \\
$\rho_{i}$ & Sea ice density & $9.0 \times 10^{2} \mathrm{~kg} \mathrm{~m}^{-3}$ \\
$\rho_{w}$ & Sea water density & $1.026 \times 10^{3} \mathrm{~kg} \mathrm{~m}^{-3}$ \\
$C_{d a}$ & Air drag coefficient & $1.2 \times 10^{-3}$ \\
$C_{d w}$ & Water drag coefficient & $5.5 \times 10^{-3}$ \\
\hline
\end{tabular}


a)

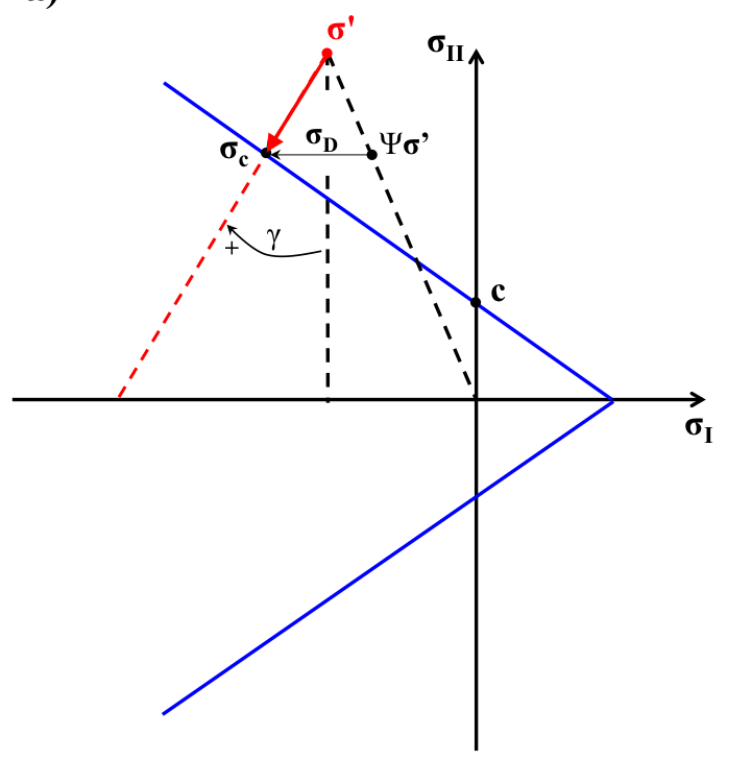

b)

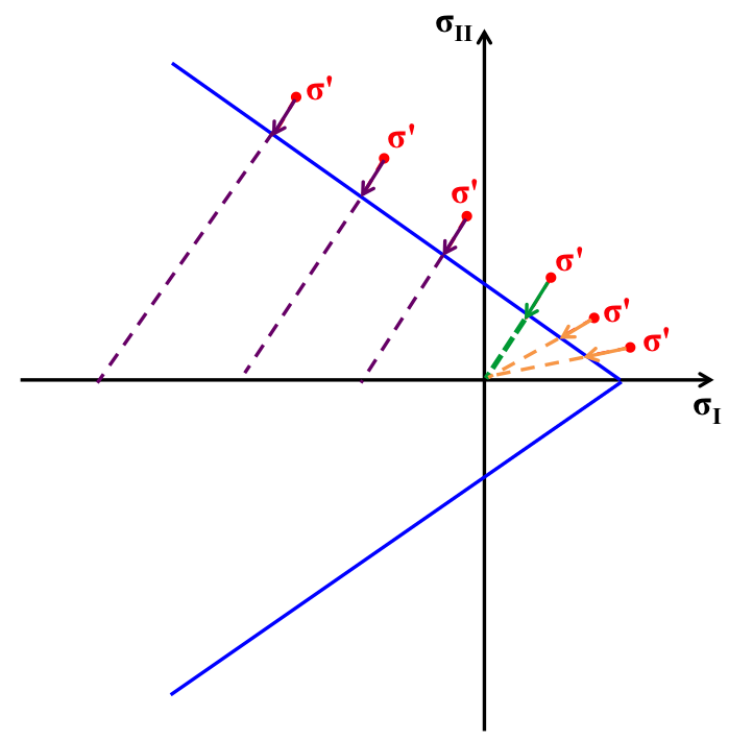

Figure 1. a) Mohr-Coulomb yield criterion in stress invariant space. $\sigma^{\prime}$ is the uncorrected super-critical stress state, $\sigma_{c}$ the critical stress state for a given correction path angle $\gamma$ (red dashed line) and $c$ is the cohesion. The decohesive stress tensor $\boldsymbol{\sigma}_{D}$ is defined as the difference between $\sigma_{c}$ and the scaled super-critical stress $\left(\Psi \sigma^{\prime}\right)$. b) Proposed correction paths for various super-critical stresses $\sigma^{\prime}$ that minimizes the error amplification ratio (R), which consist of the standard parameterization for large tensile stresses (orange) and a correction path with $\gamma=$ $45^{\circ}$ for small tensile and compressive stresses (purple). The green line indicates the transition between the two formulations. 
https://doi.org/10.5194/tc-2020-354

Preprint. Discussion started: 2 February 2021

(c) Author(s) 2021. CC BY 4.0 License.

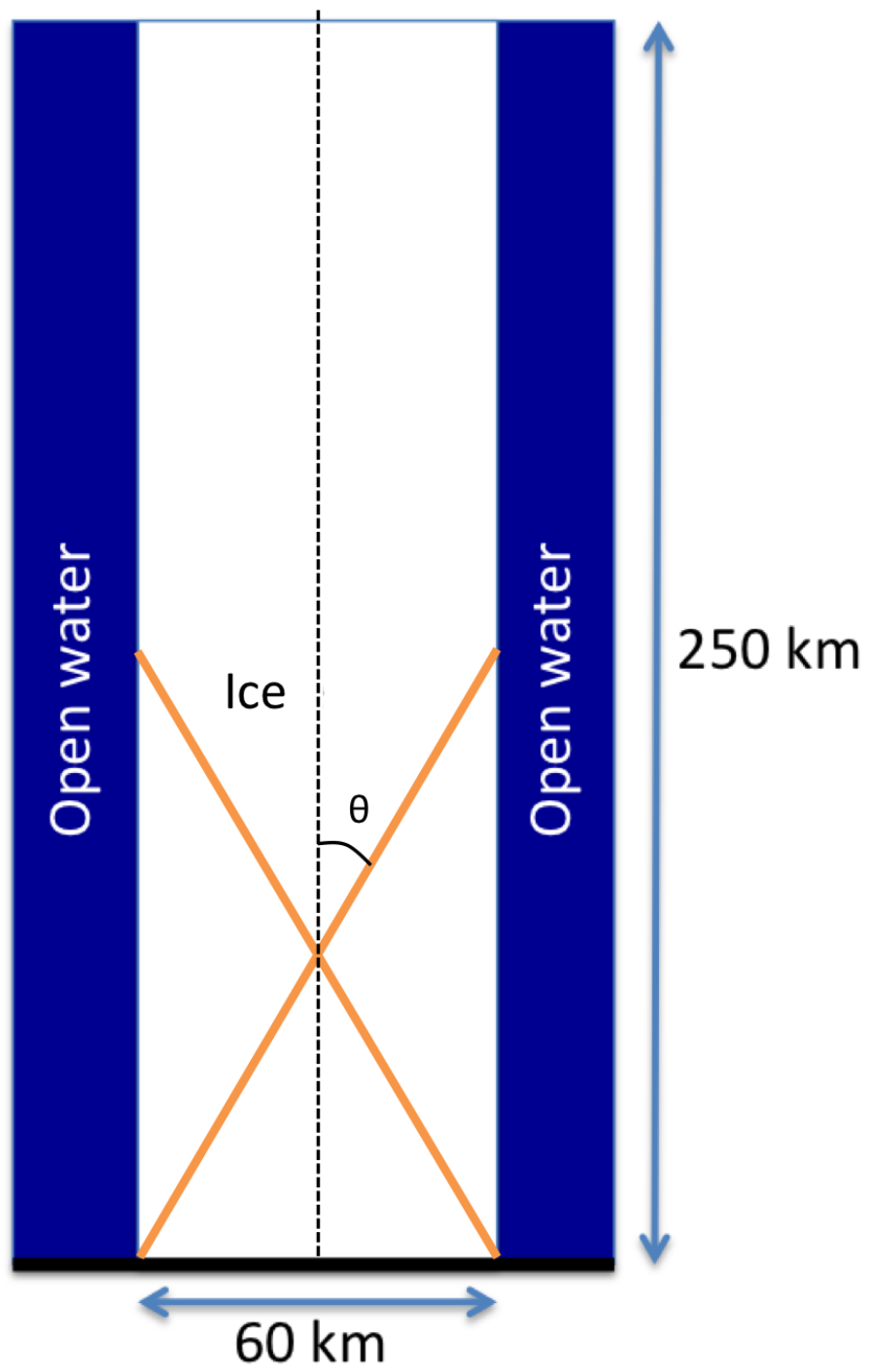

Figure 2. Idealized domain for uniaxial compression simulations, with a solid boundary (Dirichlet conditions, $u=v=0$ ) at the bottom, and open boundaries (Neumann conditions, $\partial u / \partial n=0$ ) on the sides and top. The initial conditions are $\mathrm{h}=1 \mathrm{~m}$ and $\mathrm{A}=100 \%$ in a region of 250 x $60 \mathrm{~km}$ in the center of the domain (white), with two $20 \mathrm{~km}$ wide bands of open water on each side (blue). The fracture angle $(\theta)$ is defined as half of the angle between conjugate pairs of fracture lines (Orange lines). 
https://doi.org/10.5194/tc-2020-354

Preprint. Discussion started: 2 February 2021

(c) Author(s) 2021. CC BY 4.0 License.

\section{(c) (i)}

a)

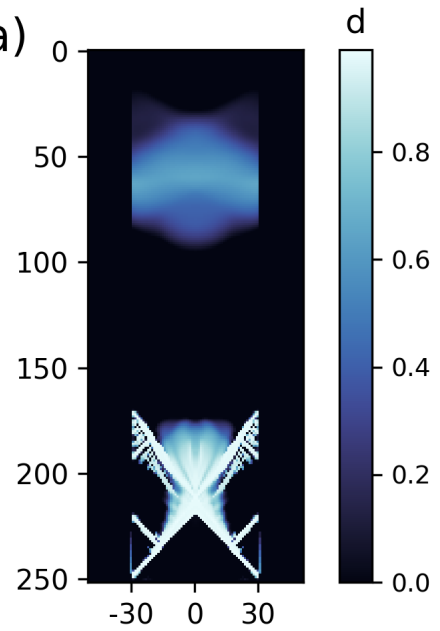

c)

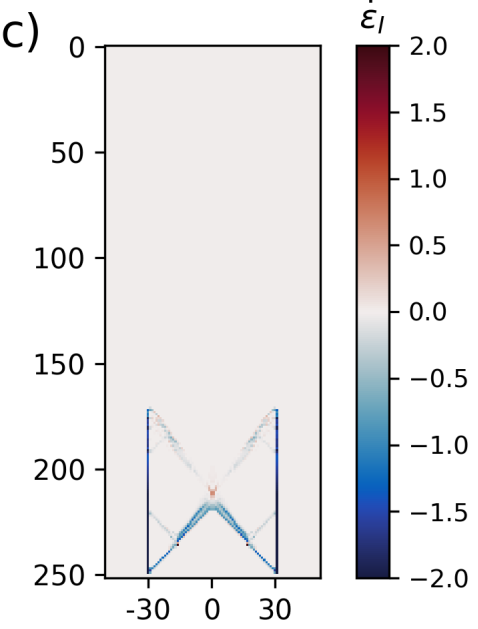

b)

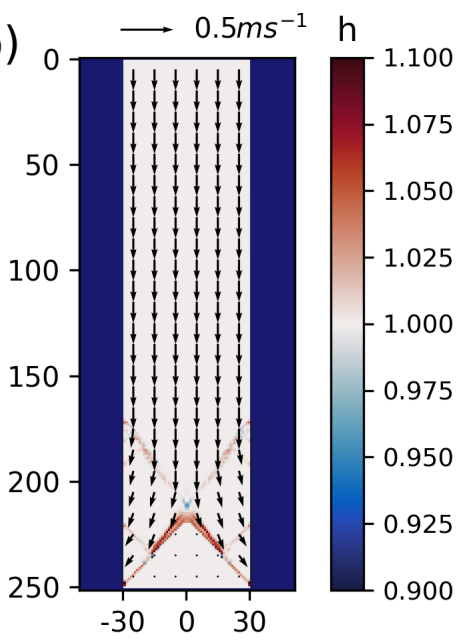

d)

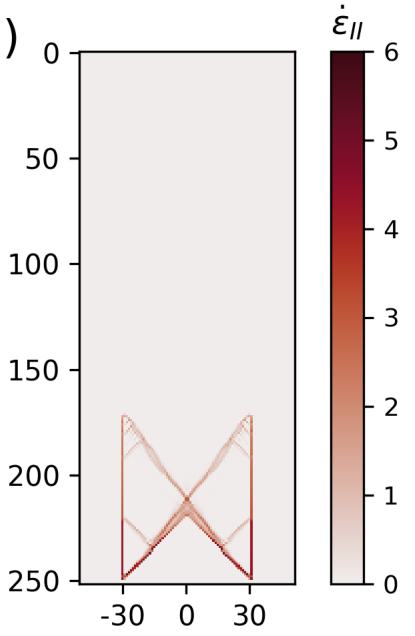

Figure 3. a) Damage (unitless), b) ice thickness (m, color) and velocity vectors $\left(\mathrm{m} \mathrm{s}^{-1}\right)$, c) mean normal strain rate invariant $\left(\dot{\epsilon}_{I}\right.$, day $\left.{ }^{-1}\right)$ and d) miximum shear strain rate invariant $\left(\dot{\epsilon}_{I I}\right.$, days $\left.{ }^{-1}\right)$, after two hours of integration in the control simulation using the standard stress correction scheme. 
a)

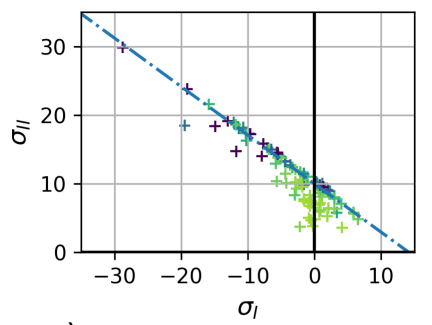

c)

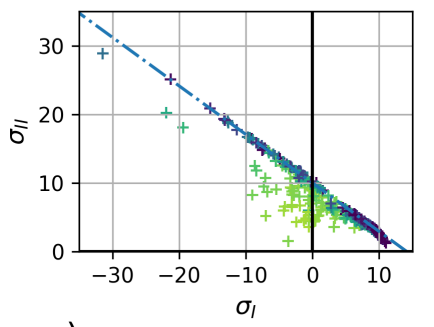

e)

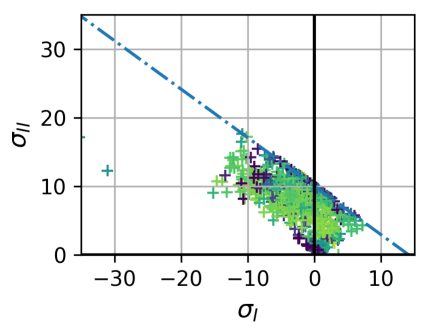

b)

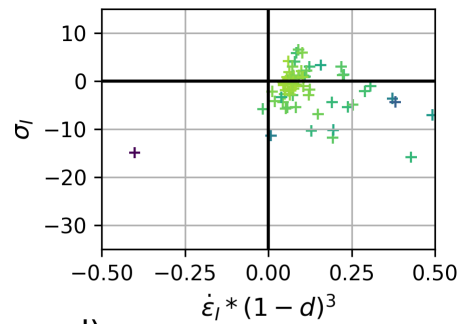

d)

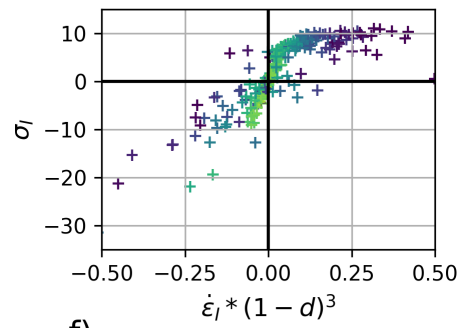

f)

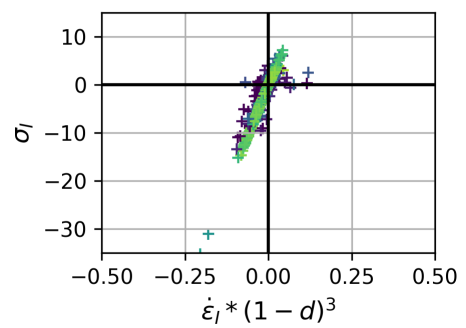

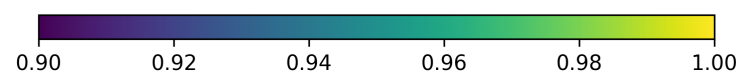

Figure 4. Stress invariants $\left(\mathrm{kN} \mathrm{m}^{-1}\right.$, left column) and normal strain rate invariant scaled by the $(1-d)^{3}\left(\right.$ day $\left.{ }^{-1} \mathrm{x} 10^{3}\right)$ as a function of the normal stress invariant $\left(\mathrm{kN} \mathrm{m}^{-1}\right.$, right column), in the control simulation for $\mathrm{t}=60$ min (top row), $\mathrm{t}=120$ min (middle row) and $\mathrm{t}=180 \mathrm{~min}$ (bottom row). 
https://doi.org/10.5194/tc-2020-354

Preprint. Discussion started: 2 February 2021

(c) Author(s) 2021. CC BY 4.0 License.

a)

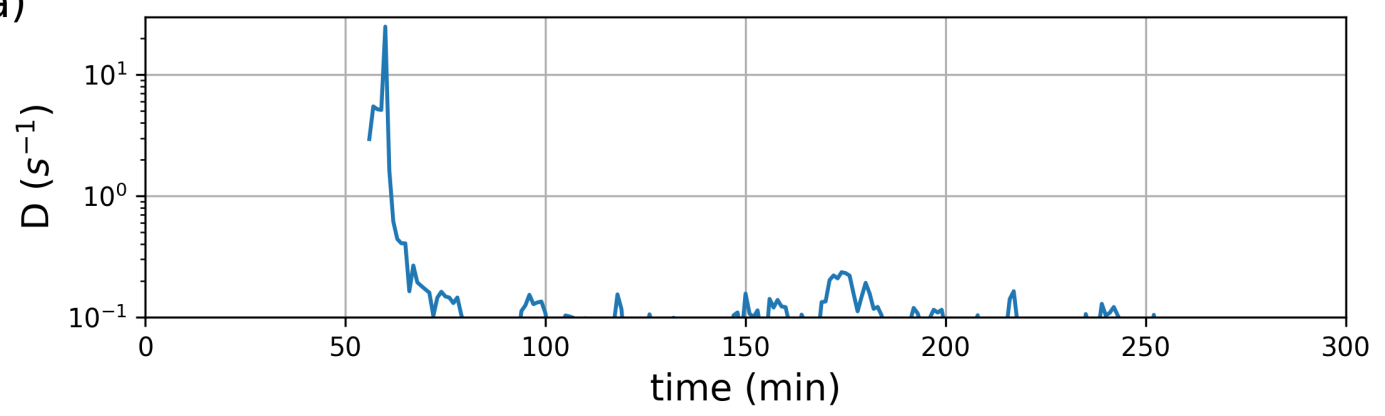

b)

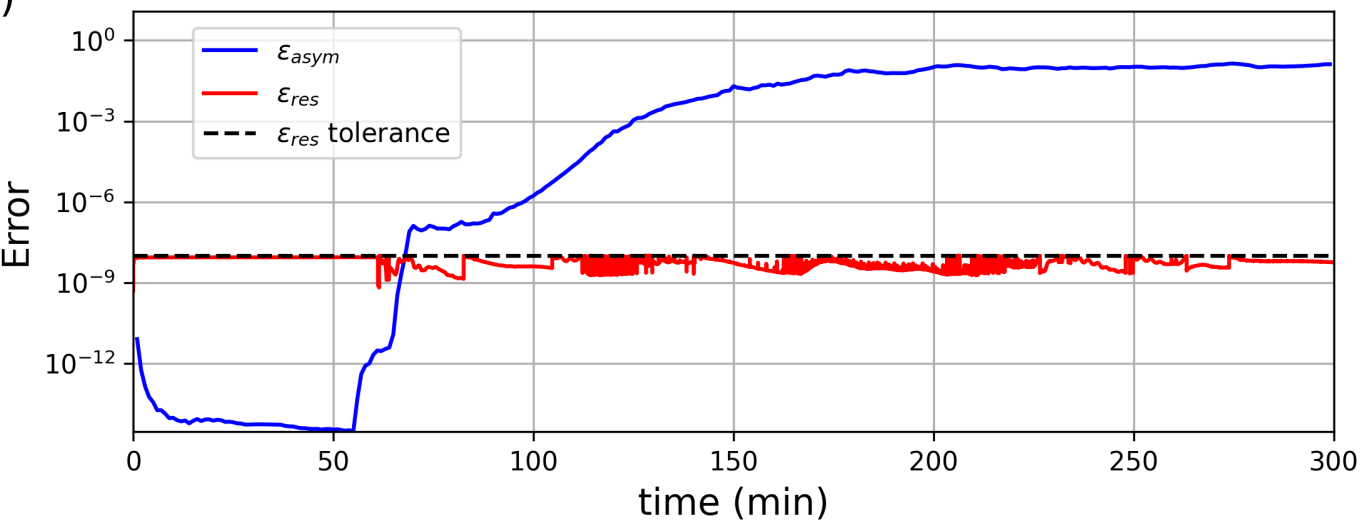

c)

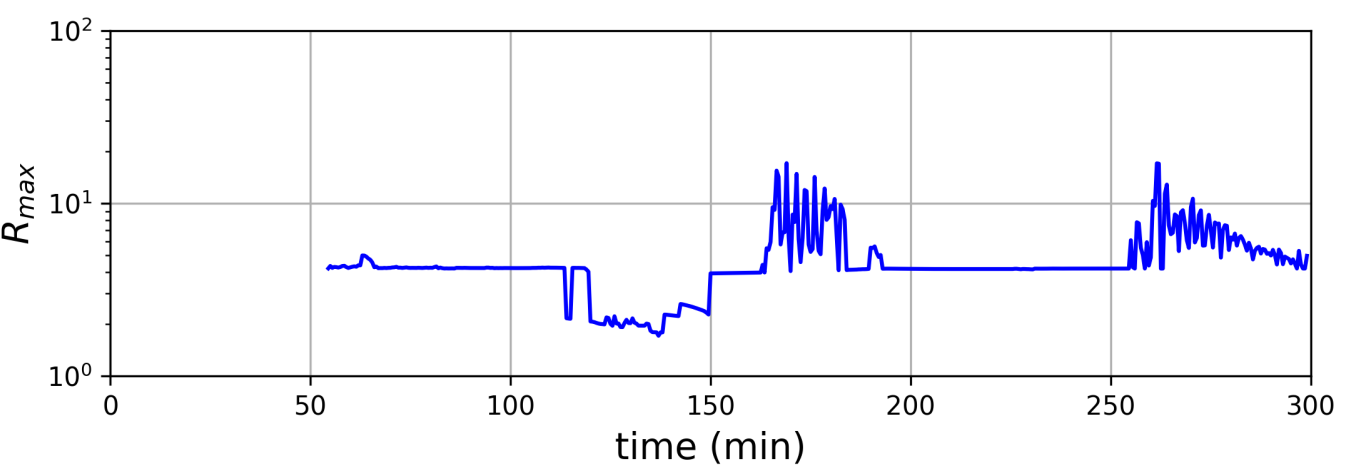

Figure 5. a) Temporal evolution of the damage activity $D$, b) the solution residual $\epsilon_{\text {res }}$, asymmetry factor $\epsilon_{\text {asym }}$ and convergence criterion on $\epsilon_{r e s}$, and c) the maximum error amplification ratio $R_{\max }$, in the control simulation using the standard stress correction scheme. 

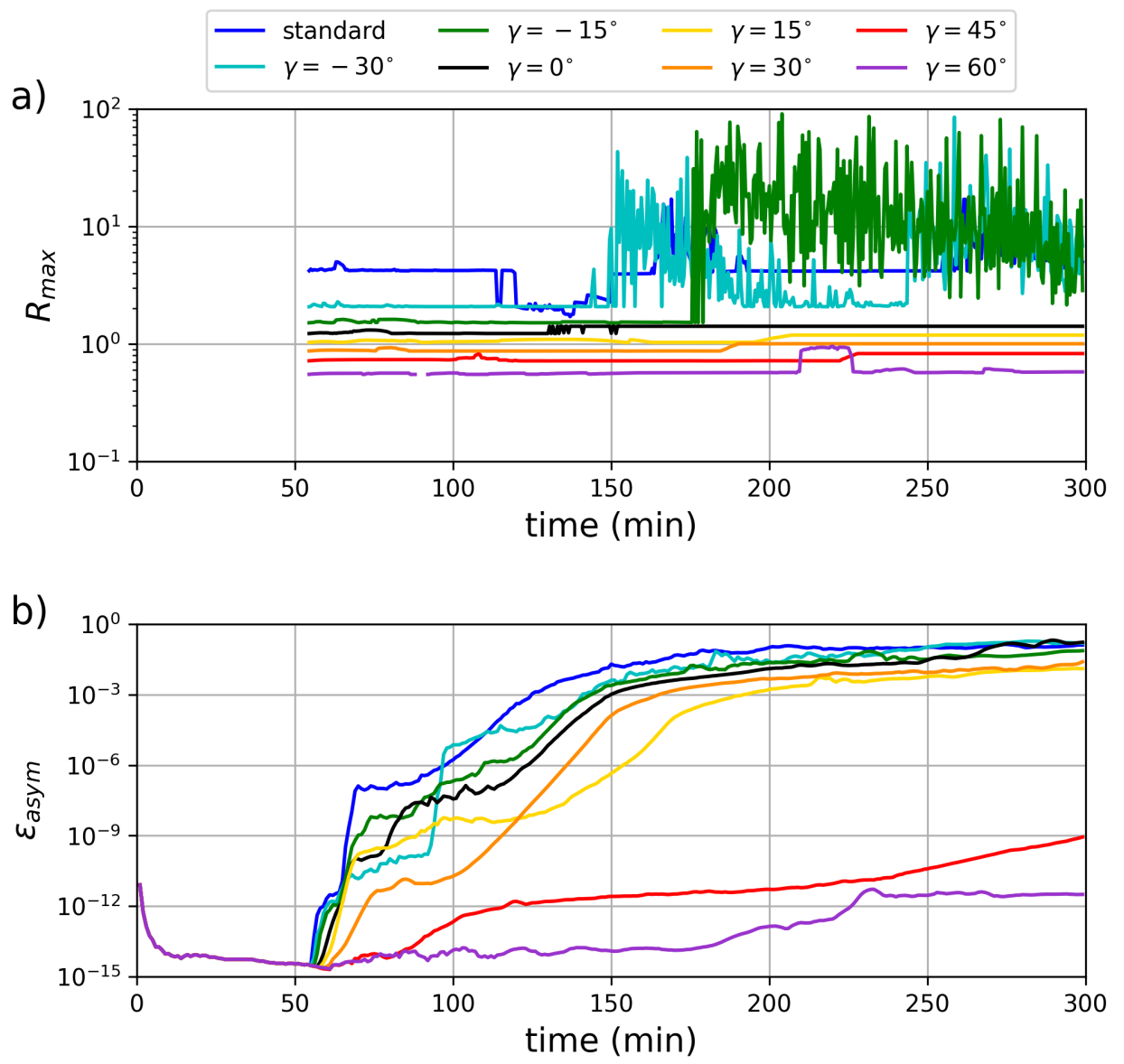

Figure 6. a) Temporal evolution of the maximum error amplification ratio $R_{\max }$ and b) the asymmetry factor $\epsilon_{\text {asym }}$, in a sensitivity experiment on the stress correction path angle $\gamma$, using the generalized stress correction scheme. 
https://doi.org/10.5194/tc-2020-354

Preprint. Discussion started: 2 February 2021

(c) Author(s) 2021. CC BY 4.0 License.

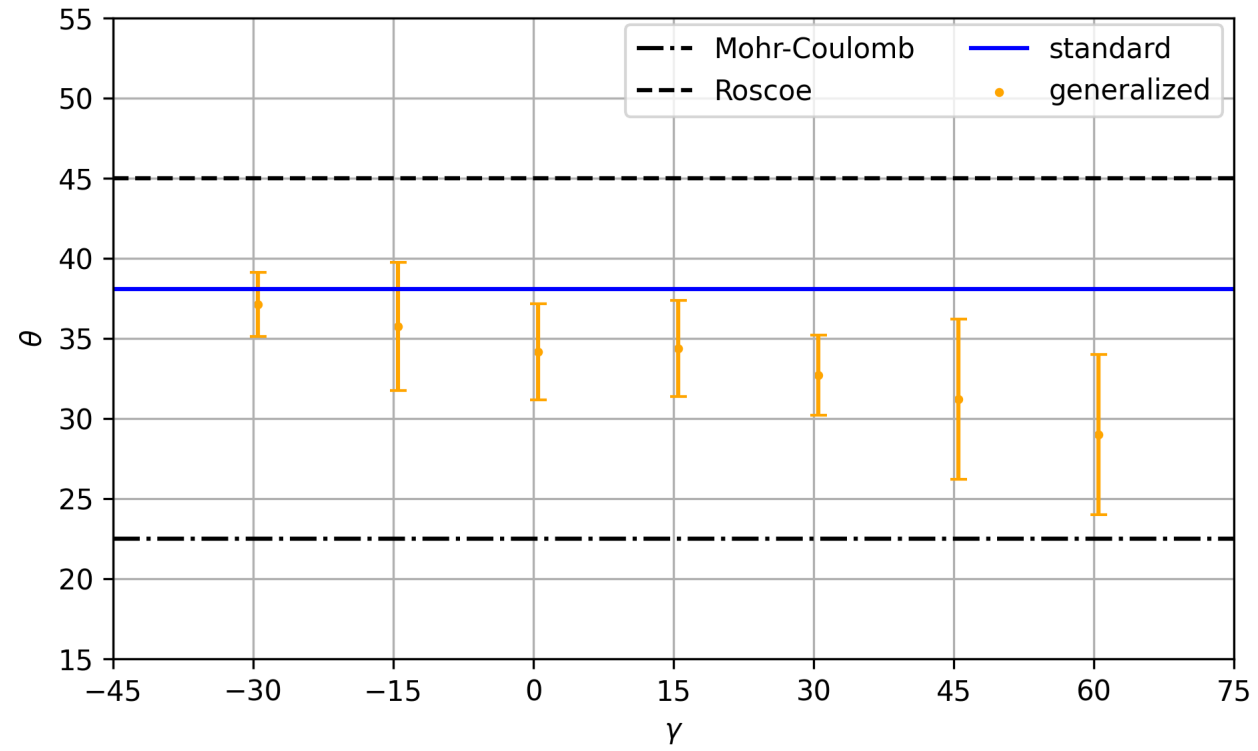

Figure 7. Sensitivity of the fracture angle $\theta$ on the stress correction path angle $\gamma$ (degrees) in uniaxial loading experiments using the generalized stress correction schemes. 


$$
\gamma=-30^{\circ}-\gamma=0^{\circ}-\gamma=30^{\circ} \longrightarrow \gamma=45^{\circ}-\gamma=60^{\circ}
$$

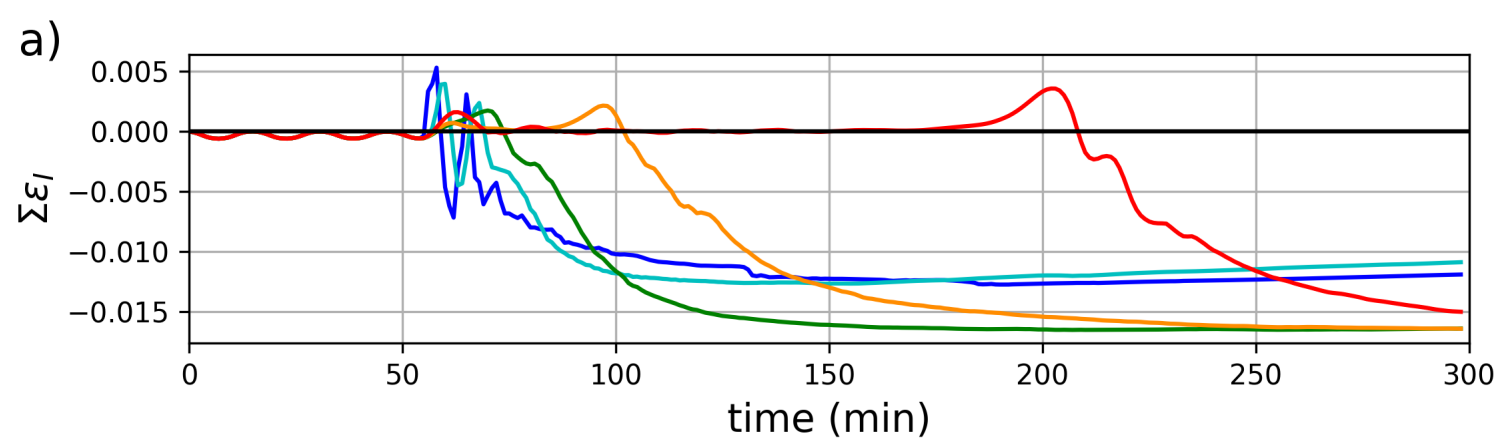

b)

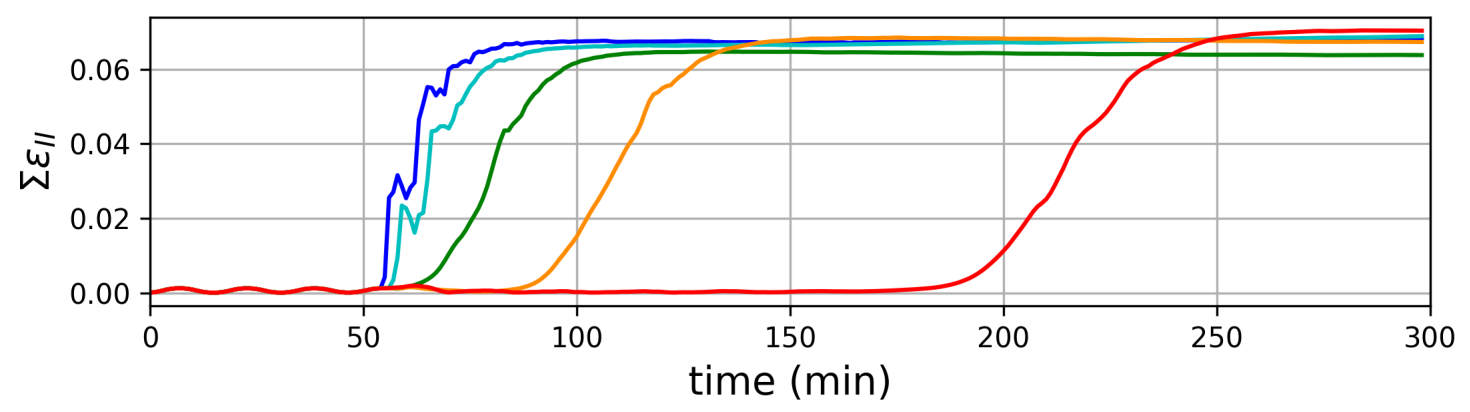

Figure 8. Time evolution of the mean normal (a) and maximum shear (b) strain rate invariants integrated over the ice cover, in simulations using the generalized damage parameterization with different stress correction path $\gamma$. 


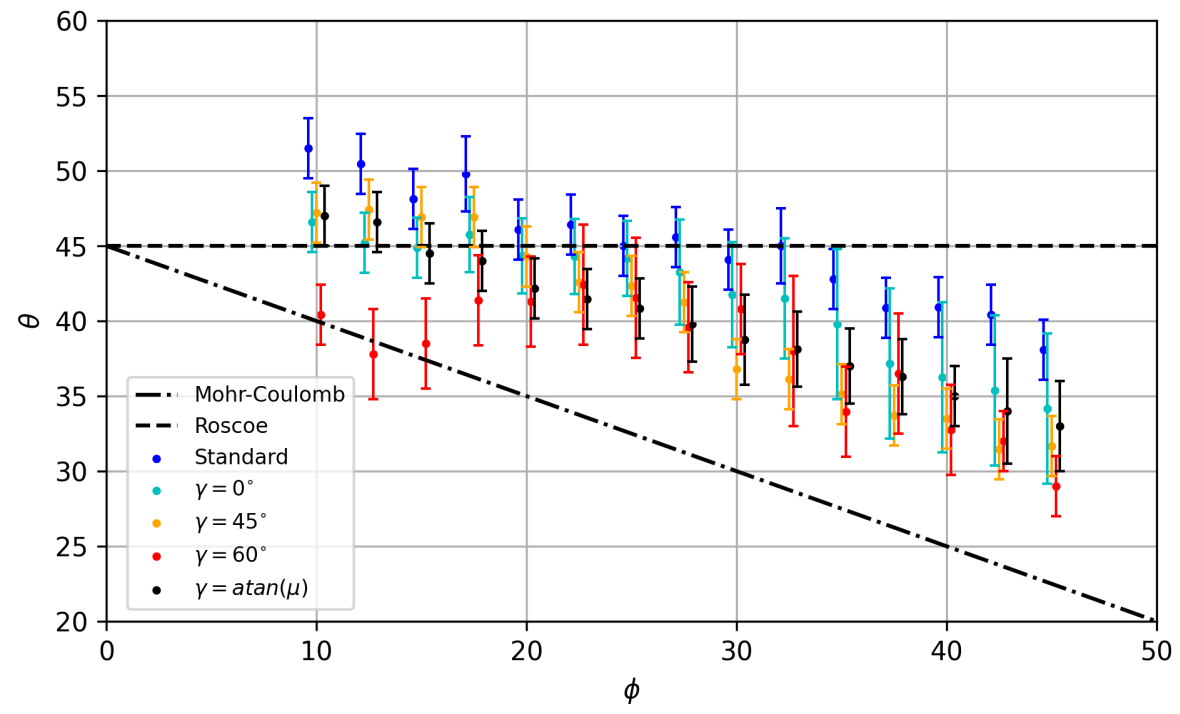

Figure 9. Sensitivity of the fracture angles ( $\theta$, degrees) on the angle of internal friction ( $\phi$, degrees), in uniaxial loading experiments using different correction path angle $(\gamma)$. The correction path angle $\gamma=\operatorname{atan}(\mu)$ implies that the stress correction path is perpendicular to the yield curve. The theoretical fracture angle from the Mohr-Coulomb and Roscoe theories are indicated by dashed and dash-dotted lines for reference. 


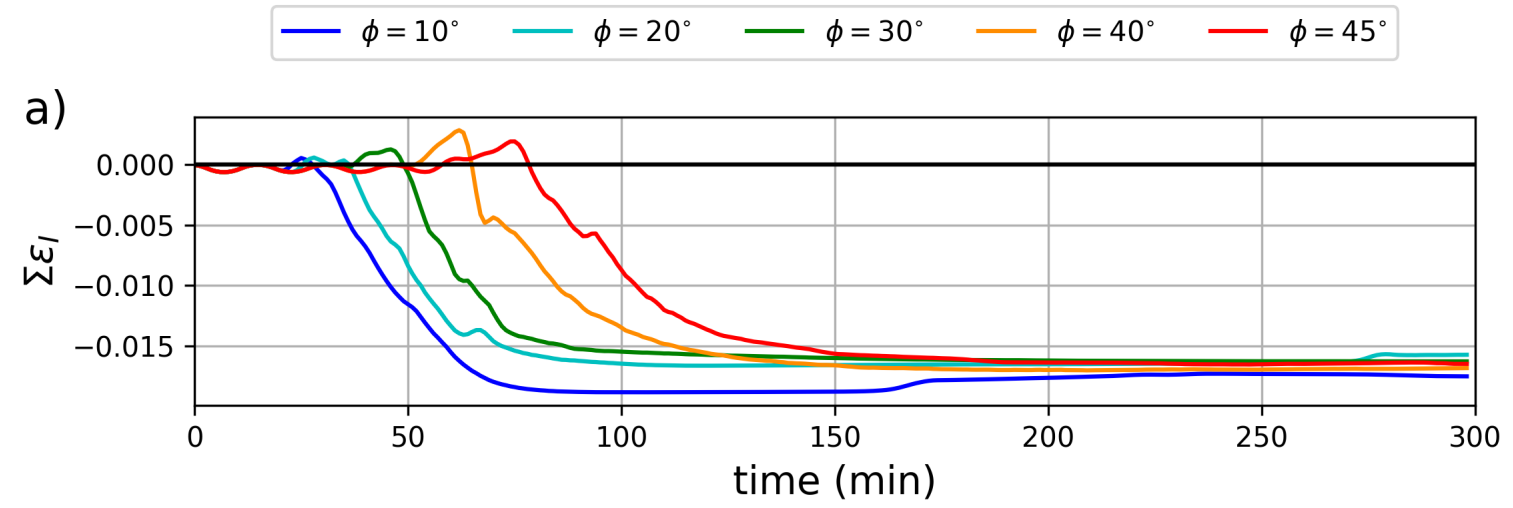

b)

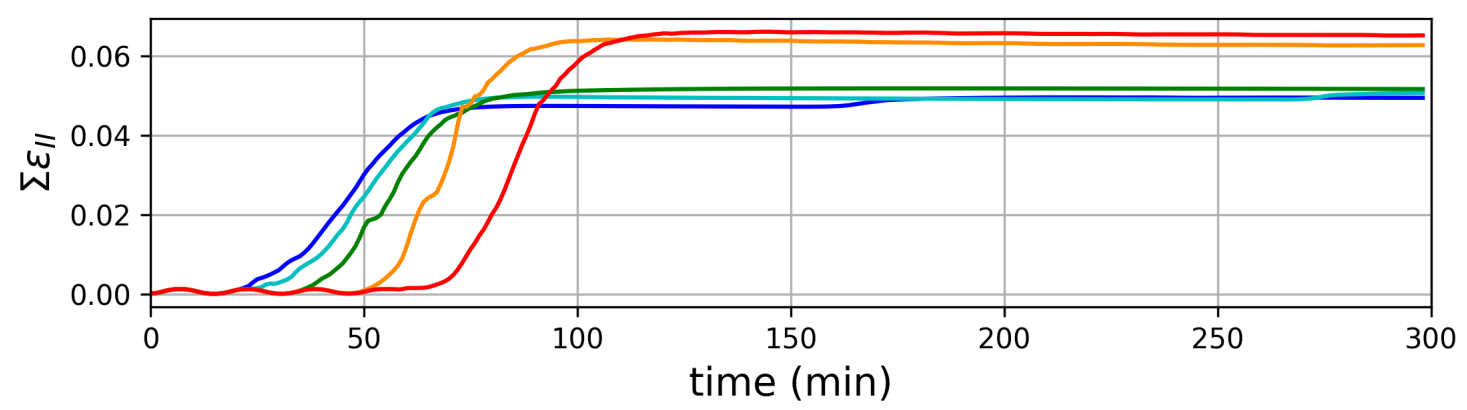

Figure 10. Time evolution of a) the mean normal strain rate invariant integrated over the ice cover $\left(\right.$ day $^{-1}$ ) and b) the maximum shear strain rate invariant integrated over the ice cover $\left(\right.$ day $\left.^{-1}\right)$, when using different angles of internal friction $\phi$, with a stress correction path normal to the yield curve $(\gamma=\arctan (\mu))$. 
https://doi.org/10.5194/tc-2020-354

Preprint. Discussion started: 2 February 2021

(c) Author(s) 2021. CC BY 4.0 License.

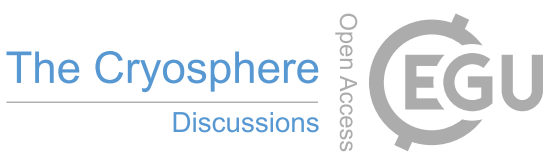
(c) (i)

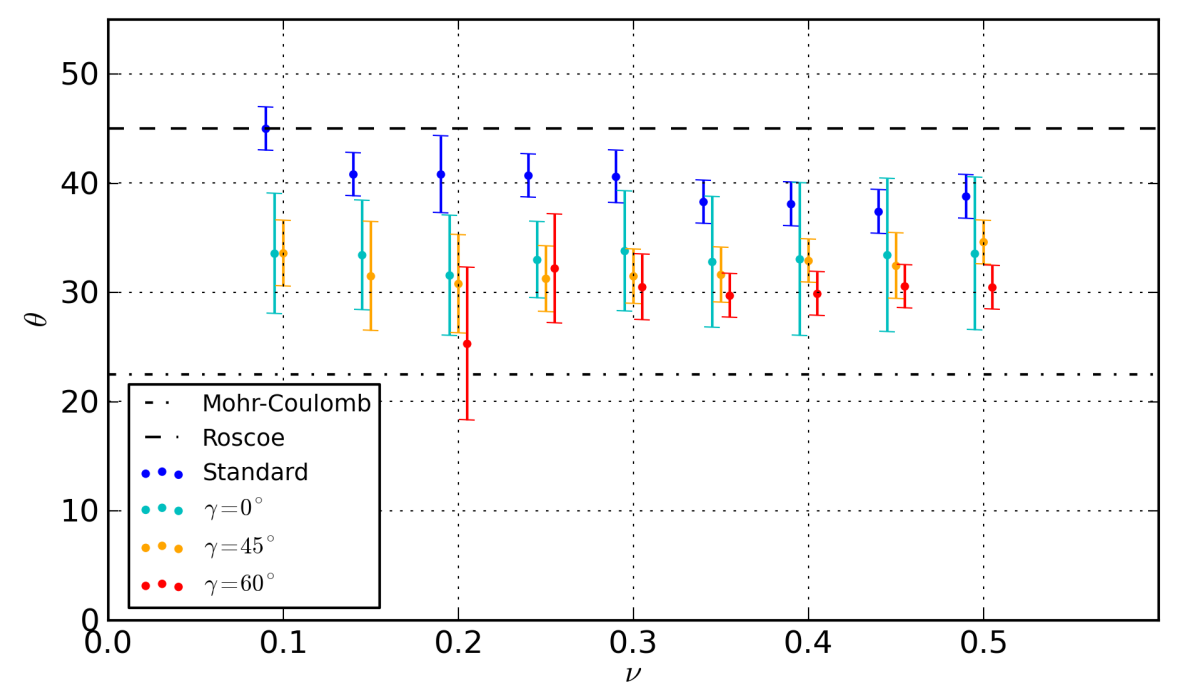

Figure 11. Sensitivity of the fracture angles $(\theta$, degrees) on the Poisson ratio ( $\nu$, unitless), in uniaxial loading experiments using different correction path angle $(\gamma)$. The theoretical fracture angle from the Mohr-Coulomb and Roscoe theories are indicated by dashed and dash-dotted lines for reference. 
https://doi.org/10.5194/tc-2020-354

Preprint. Discussion started: 2 February 2021

(c) Author(s) 2021. CC BY 4.0 License.

The Cryosphere

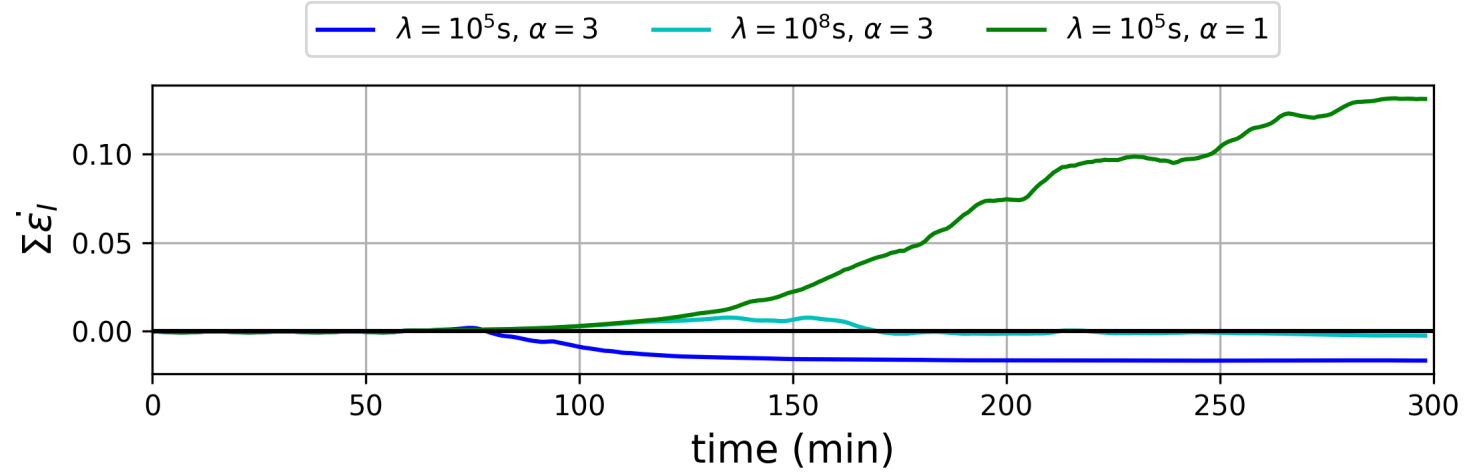

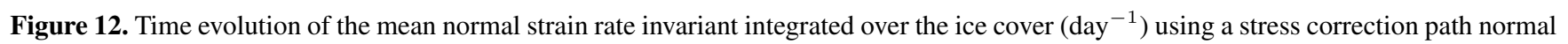
to the yield curve $(\gamma=\arctan (\mu))$ with $\alpha=3$ (blue), $\alpha=1$, and a longer viscous dissipation time-scale $\left(\lambda=10^{8} \mathrm{~s}\right)$. 
a)

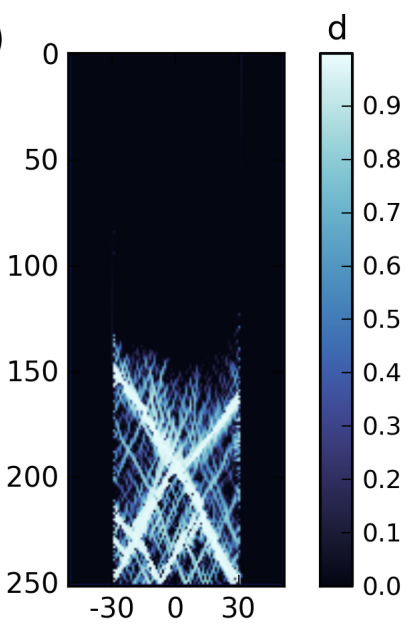

c)

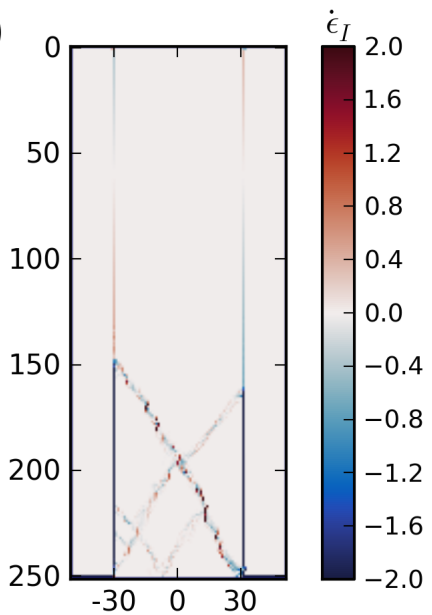

b)

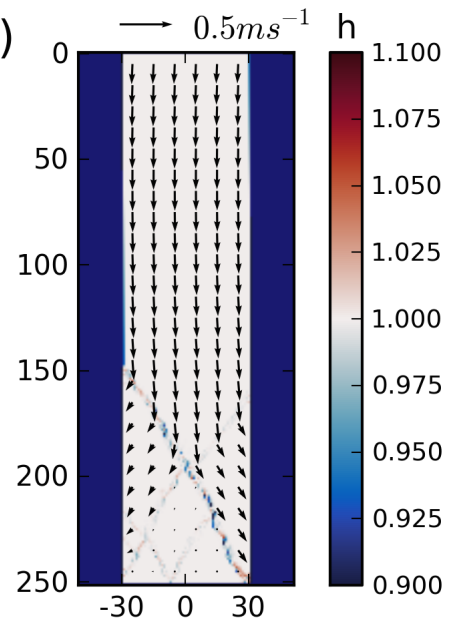

d)

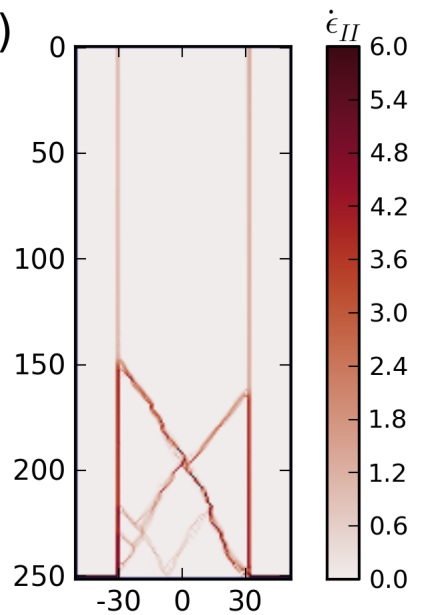

Figure 13. a) Damage (unitless), b) ice thickness (m, color) and velocity vectors $\left(\mathrm{m} \mathrm{s}^{-1}\right)$, c) mean normal strain rate invariant $\left(\dot{\epsilon}_{I}\right.$, day $\left.{ }^{-1}\right)$ and d) maximum shear strain rate invariant $\left(\dot{\epsilon}_{I I}\right.$, days $\left.{ }^{-1}\right)$ after two hours of integration in using the generalized stress correction scheme with $\gamma=45^{\circ}$ and including heterogeneity in the initial material cohesion field. The heterogeneous cohesion $\left(c_{0}\right)$ field is defined locally at each grid cell by picking a random number between 7.0 and $13.0 \mathrm{kN} \mathrm{m}^{-2}$. The remaining initial conditions are the same as all other simulations. 